\title{
Abnormal CCK/CB1R axon targeting in mouse models of dystroglycanopathy
}

Daniel S. Miller ${ }^{1}$, Jennifer N. Jahncke ${ }^{1}$, Eric Schnell ${ }^{2,3}$, and Kevin M. Wright ${ }^{4, \#}$

${ }^{1}$ Neuroscience Graduate Program, Oregon Health \& Science University, Portland, OR 97239, USA

${ }^{2}$ Operative Care Division, Portland VA Health Care System

${ }^{3}$ Anesthesiology and Perioperative Medicine, Oregon Health \& Science University, Portland, OR 97239, USA

${ }^{4}$ Vollum Institute, Oregon Health \& Science University, Portland, OR 97239, USA

\#) Correspondence to Kevin M Wright (wrighke@ohsu.edu). Vollum Institute, 3181 SW Sam Jackson Park Rd L474 Portland, OR 97239. (503)-494-6955

Keywords: Dystroglycan, dystroglycanopathy, cannabinoid receptor, cholecystokinin, interneuron, synapse

Competing interests: The authors declare that they have no competing interests.

\section{Acknowledgments}

This work was funded by NIH Grants R01NS091027 (KMW), CureCMD (KMW), F31NS108522 (DSM), F31NS120649 (JNJ), P30NS061800 (OHSU ALM), VA I01BX004938 (ES), Department of Defense W81XWH-18-1-0598 (ES), and a Tartar Trust Fellowship (DSM). The contents of this manuscript do not represent the views of the US Department of Veterans Affairs or the US government. 


\begin{abstract}
Dystroglycan (Dag1) is a cell adhesion molecule that links the extracellular matrix
\end{abstract} to the actin cytoskeleton, and is critical for normal muscle and brain development. Mutations in Dag1 or the genes required for its functional glycosylation result in dystroglycanopathy, which is characterized by a wide range of phenotypes including muscle weakness, brain defects, and cognitive impairments. Whereas Dystroglycan's role in muscle and early brain development are well defined, much less is known about its role at later stages of neural circuit development including synapse formation and refinement. Recent work has found that selective deletion of Dag1 from pyramidal neurons leads to a loss of presynaptic CCK+ inhibitory neurons (INs) early in development. In this study, we investigated how IN development is affected in multiple mouse models of dystroglycanopathy. Widespread forebrain deletion of Dag1 or Pomt2, which is required for Dystroglycan glycosylation, recapitulates brain phenotypes seen in severe forms of dystroglycanopathy. CCK+ INs were present in Dag1 and Pomt2 mutant mice, but their axons failed to properly target the somatodendritic compartment of pyramidal neurons in the hippocampus. In contrast, CCK+ IN axon targeting was largely normal in mouse models of mild dystroglycanopathy with partially reduced Dystroglycan glycosylation (B4gat1, Fkrp). Furthermore, the intracellular domain of Dystroglycan appears to be dispensable for CCK+ IN axon targeting. Collectively, these data show that synaptic defects are a hallmark of severe dystroglycanopathy. 


\section{INTRODUCTION}

The formation of neural circuits is a multistep process involving proliferation, migration, axon guidance, neurochemical and morphological maturation of neuronal subtypes, and establishment of functional synaptic connections between neurons. Cell adhesion molecules (CAMs) play critically important roles and often function reiteratively at multiple stages of neural circuit development. Many CAM families are present at excitatory and/or inhibitory synapses, including Neurexins/Neuroligins, Cadherins/Protocadherins, Slitrks, SynCAMs, LRR (leucine rich repeat) proteins, and Ephrins/Ephs, among others (Chanda et al., 2017; Chen et al., 2017; Dalva et al., 2007; Giagtzoglou et al., 2009; Pettem et al., 2003; Takahashi et al., 2012; Krueger-Burg et al., 2017). Synaptic CAMs often act in parallel and redundantly to ensure the fidelity of synapse formation and function.

Dystroglycan, a CAM widely expressed in muscle and brain, is present in the post-synaptic compartment of inhibitory synapses throughout the central nervous system (CNS). Dystroglycan is a central component of the dystrophin-glycoprotein complex (DGC) known primarily for its role in the etiology of neuromuscular diseases including Duchenne muscular dystrophy (DMD), Limb-girdle muscular dystrophy (LGMD), and Congenital muscular dystrophy (CMD). The gene encoding Dystroglycan (Dag1) yields two subunits, the extracellular alpha dystroglycan ( $\alpha-D G)$ and the transmembrane beta dystroglycan ( $\beta-D G)$. These two subunits are non-covalently linked, allowing Dystroglycan to function as a link between extracellular ligands and cytoskeletal and signaling proteins (Ervasti and Campbell, 1991; Holt et al., 2000; Ibraghimov-Beskrovnaya et al., 1992; Moore and Winder, 2010). Extracellular $\alpha-D G$ 
binds multiple proteins in the nervous system including Laminins, Perlecan, Agrin, Pikachurin, Slits, Neurexins, and Celsr3 (Campanelli et al., 1994; Dempsey et al., 2019;

Gee et al., 1994; Ibraghimov-Beskrovnaya et al., 1992; Lindenmaier et al., 2019; Peng et al., 1998; Sato et al., 2008; Sugita et al., 2001; Sugiyama et al., 1994; Wright et al., 2012). These proteins all contain at least one Laminin G (LG) domain that binds to sugar moieties present on $\alpha-D G$. The glycosylation of Dystroglycan is required for LG domain binding, and over 18 genes have been identified that participate in the synthesis of the O-mannosyl linked glycan chains on $\alpha-D G$ (Manya and Endo, 2017). Mutations in these genes impair Dystroglycan function through reduced ligand binding, and lead to dystroglycanopathy, a form of congenital muscular dystrophy with a wide range of muscle and brain phenotypes (Blaeser et al., 2013). Patients with severe forms of dystroglycanopathy frequently present with structural brain abnormalities and exhibit seizures and cognitive impairments (Barresi and Campbell, 2006; Muntoni et al., 2011; Taniguchi-lkeda et al., 2016). Dystroglycanopathy patients with moderate severity can exhibit cognitive impairments even in the absence of identifiable brain malformations, suggesting that Dystroglycan functions at later stages of neural circuit formation such as synapse formation and/or maintenance (Godfrey et al., 2007; Clement et al., 2008).

Within the brain, Dystroglycan is expressed in radial glia, pyramidal neurons, astrocytes, and oligodendrocytes where it plays important roles in the formation of basement membranes during early brain development (Colognato et al., 2007; Nguyen et al., 2013; Nickolls and Bonnemann, 2018; Tian et al., 1996; Zaccaria et al., 2001). Mice lacking Dag1 from the CNS recapitulate many of the phenotypes of severe dystroglycanopathy, including cortical malformation and hydrocephalus. Cortical 
neurons in these mice fail to migrate properly and cortical layering is severely disrupted due to disruption of Dystroglycan function in the neuroepithelium and radial glia (Myshrall et al., 2012; Satz et al., 2008, 2010). At later developmental stages, Dystroglycan is present at multiple synapses throughout the peripheral and central nervous system, including at photoreceptor ribbon synapses in the retina (Omori et al., 2012; Orlandi et al., 2018), inhibitory synapses in the cerebellum (Briatore et al., 2010, 2020; Patrizi et al., 2008), and at a subset of GABAergic inhibitory synapses onto pyramidal neurons in the cortex and hippocampus (Brunig et al., 2002; Levi et al., 2002). Recent studies have demonstrated that when Dag1 is selectively deleted from pyramidal neuron (PyNs), neuronal migration and lamination is normal. However, cholecystokinin interneurons $(\mathrm{CCK}+\mathrm{INs})$ fail to populate the forebrain or form cannabinoid receptor-1 $\left(\mathrm{CB}_{1} \mathrm{R}\right)$ positive synapses in these mice (Fruh et al., 2016; Miller and Wright, 2021). These studies establish a critical role for Dystroglycan function at a subset of inhibitory synapses in the brain.

Here, we address several outstanding questions related to the role of Dystroglycan at inhibitory synapses. We show that in severe models of dystroglycanopathy, $\mathrm{CCK}+/ \mathrm{CB}_{1} \mathrm{R}+\mathrm{INs}$ are present, but their somatodendritic axon targeting and synapse formation are abnormal. In contrast, models of mild dystroglycanopathy display relatively normal $C C K+/ C B_{1} R+I N$ development. Furthermore, we find that $\mathrm{CCK}+/ \mathrm{CB}_{1} \mathrm{R}+\mathrm{IN}$ axon targeting and synapse formation is dependent on proper Dystroglycan glycosylation, but the intracellular domain is largely dispensable. Together, these results have important implications for understanding the synaptic defects in dystroglycanopathy. 


\section{RESULTS}

\section{Forebrain deletion of Dystroglycan models severe dystroglycanopathy}

To model severe dystroglycanopathy, we generated two independent conditional knockout (cKO) mouse lines lacking Dystroglycan from the forebrain. Dystroglycan floxed mice $\left(\operatorname{Dag} 1^{F / F}\right)$ (Cohn et al., 2002) were crossed with either Nestin ${ }^{\text {Cre }}$ or $E m \times 1^{\text {Cre }}$ mice which both drive recombination in forebrain progenitors (Tronche et al., 1999; Gorski et al., 2002; Graus-Porta et al., 2001; Guo et al., 2000) (Fig. 1A). Recombination

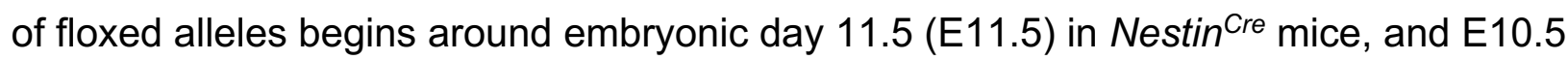

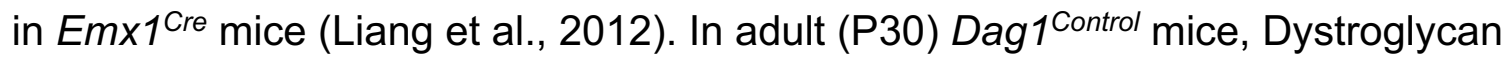
staining was observed prominently on blood vessels throughout the brain, as well as puncta concentrated on the cell bodies and proximal dendrites of pyramidal neurons (PyNs), consistent with its synaptic localization (Fig. 1B). In contrast, Dystroglycan staining was absent from PyNs and blood vessels in Dag $1^{\text {ckO }}$ mice (Fig 1B). In agreement with previous work, Nestin ${ }^{\mathrm{Cre}} ; \mathrm{Dag} 1^{\mathrm{cKO}}$ mice exhibited severe disruption of normal cortical architecture revealed by both immunohistochemical staining for layer markers and genetic labeling of layer 5 pyramidal neurons using the Thy $1^{\text {YFP }}$ reporter line (Fig. 1C; Satz et al., 2010; Myshrall et al., 2012). Deletion of Dystroglycan using $E m \times 1^{\text {Cre }}$ resulted in similar neuronal migration defects, revealed by immunostaining for cortical layer markers CUX1 (upper layers, 2-4) and CTIP2 (deep layers, 5-6) (Fig. 1D). In both Dag1cko lines, the loss of normal cortical layering and presence of heterotopia recapitulate the type II lissencephaly phenotype observed in human patients with severe dystroglycanopathy. 


\section{Dystroglycan is required non-cell autonomously for CCK+ interneuron axon targeting}

Cholecystokinin and cannabinoid receptor-1 expressing interneurons $\left(\mathrm{CCK}+/ \mathrm{CB}_{1} \mathrm{R}+\mathrm{INs}\right)$ are largely absent from the cortex and hippocampus when Dag1 is deleted selectively from PyNs using NEX're (Fruh et al., 2016; Miller and Wright, 2021). However, it is unknown whether these INs migrate and properly innervate their synaptic targets in mouse models that lack Dag1 throughout the CNS, and therefore more closely recapitulate dystroglycanopathy. We focused our analysis on the hippocampus, as its architecture and synaptic layers are largely unaffected in Dag $1^{\mathrm{ckO}}$ mice (Fig. 2AD). In Nestin ${ }^{\mathrm{Cre}} ; \mathrm{Dag} 1^{\text {Control }}$ mice, $\mathrm{CB}_{1} \mathrm{R}+\mathrm{IN}$ axon terminals were abundant throughout the hippocampus (Fig. 2A), with their highest density in the cell body layers (CA1-3) where they form characteristic basket synapses onto PyNs (Fig. 2A'-A"). CCK+ INs were also present in the hippocampus of $\mathrm{Nestin}^{\mathrm{Cre}} ; \mathrm{Dag}{ }^{\mathrm{ckO} O}$ mice, but their $\mathrm{CB}_{1} \mathrm{R}+$ axon terminals were noticeably reduced in the PyN cell body layer (SP, stratum pyramidale) of CA1 and CA3 (Fig. 2B).

The surprising difference in $C C K+I N$ innervation between $N E X^{C r e} ; D a g 1^{1 K O}$ and Nestin ${ }^{\mathrm{Cre}} ; \mathrm{Dag} 1^{\mathrm{cKO}}$ mice led us to next examine $\mathrm{Em} \times 1^{\mathrm{Cre}} ; \mathrm{Dag} 1^{\mathrm{cKO}}$ mice. While Nestin ${ }^{\mathrm{Cre}}$ drives recombination in all neuronal and glial cells in the forebrain, Emx $1^{\text {Cre }}$ recombination is limited to dorsal forebrain, thereby sparing IN populations that migrate from the ganglionic eminences in the ventral forebrain (Guo et al., 2000; Gorski et al., 2002). We confirmed the specificity of Cre-mediated recombination in Emx $1^{\text {Cre }}$ mice by crossing it with Rosa26 Lox-STOP-Lox-H2B:mCherry reporter mice to label the nuclei of recombined cells. H2B:mCherry signal was present in excitatory neurons and astrocytes 
throughout the forebrain (Fig. S1A, B, D), but not microglia or interneurons (Fig. S1C, E). Similar to Nestin ${ }^{C r e}$;Dag1 ${ }^{\text {CKO }}, \mathrm{CCK}+$ INs were present in throughout the forebrain of $E m \times 1^{C r e} ; D a g 1^{c K O}$ mice, but their axon terminals were distributed throughout the hippocampus, rather than showing enrichment in the cell body layer (SP) of CA1 and

CA3 (Fig. 2D). We confirmed this reduction in SP innervation in Emx $1^{\text {Cre }}$ :Dag $1^{\text {cKO }}$ mice by immunostaining for VGLUT3, an independent marker for CCK+ IN axon terminals. Similar to $\mathrm{CB}_{1} \mathrm{R}$ staining, the density of VGLUT3+ axon terminals was reduced in the $\mathrm{SP}$, verifying that $\mathrm{CCK}+/ \mathrm{CB}_{1} \mathrm{R}+\mathrm{IN}$ innervation of PyNs is impaired in $\mathrm{Em \times 1}{ }^{\mathrm{Cre}} ; \mathrm{Dag} 1^{c K O}$ mice (Fig. S2). We previously found that $C \mathrm{CK}+/ \mathrm{CB}_{1} \mathrm{R}+\mathrm{INs}$ were absent in the amygdala of $N E X^{C r e} ;$ Dag $1^{c K O}$ mice (Miller and Wright, 2021). In contrast, $C C K+/ C B_{1} R+$ INs were present in the amygdala of Nestin ${ }^{\mathrm{Cre}} ; \mathrm{Dag} 1^{\text {cKO }}$ and $E m \times 1^{\mathrm{Cre}} ; \mathrm{Dag} 1^{\text {cKO }}$ mice, although their innervation was reduced (Fig. S3). Taken together, these results show that in contrast to $N E X^{C r e} ; D a g 1^{c K O}$ in which $C C K+I N s$ are largely absent from the forebrain, $\mathrm{CCK}+\mathrm{INs}$ are present in mouse models that more closely resemble severe dystroglycanopathy (Nestin ${ }^{\mathrm{Cre}} ; \mathrm{Dag} 1^{\mathrm{cKO}}$ and $\left.\mathrm{Em} \times 1^{\mathrm{Cre}} ; \mathrm{Dag} 1^{\mathrm{CKO}}\right)$, but they fail to concentrate their axon terminals to form basket synapses on the PyN cell bodies.

\section{Dystroglycan is required for proper CCK+ IN axon targeting during early postnatal development}

We next sought to identify the onset of CCK+ IN axon targeting defects in Dag $1^{\text {cKO }}$ mice. During early postnatal ages, $\mathrm{CCK}+\mathrm{IN}$ axons undergo dramatic laminar rearrangements to preferentially target PyN cell bodies in the hippocampus (Miller and Wright, 2021; Morozov et al., 2003a; 2003b; 2009). As $\mathrm{CB}_{1} \mathrm{R}$ staining is largely absent 
from CCK+ IN axons before birth, we examined the development of CCK+ IN axons beginning at $\mathrm{P} 5$ when $\mathrm{CB}_{1} \mathrm{R}+$ axons are readily visible in the hippocampus (Berghuis et al., 2007; Eggan et al., 2010; Mulder et al., 2008; Vitalis et al., 2008). At P5 in Emx1 ${ }^{\text {Cre }} ;$ Dag $1^{\text {Control }}$ mice, $\mathrm{CB}_{1} \mathrm{R}+$ axons were initially observed in the stratum radiatum (SR) of the hippocampus where immature PyN dendrites are located (Fig. 3A, C, F). Between $\mathrm{P} 10$ to $\mathrm{P} 30$, the density of $\mathrm{CB}_{1} \mathrm{R}+$ axons became significantly reduced in the SR, coinciding with a progressive increase in the pyramidal cell body layer (SP). Compared with controls, the density of $\mathrm{CB}_{1} \mathrm{R}+$ axons in the hippocampus of $E m \times 1^{\mathrm{Cre}} ; \mathrm{Dag} 1^{\mathrm{CKO}}$ mice was significantly reduced in the SP layer at all ages examined, beginning at P5 (Fig. 3B, D, E). By P30, after IN synapse formation and targeting are largely complete, the density of $\mathrm{CB}_{1} \mathrm{R}+$ axons was increased in the PyN dendrite layers (SO, SR) compared with controls. In Emx $1^{\text {Cre }} ; \mathrm{Dag} 1^{\mathrm{cKO}}$ mice at P30, the density of $\mathrm{CB}_{1} \mathrm{R}+$ axons in the SP was nearly identical to the SO and SR (Fig. 3D, F). Collectively, these results demonstrate that Dystroglycan is critical during the first two postnatal weeks for the proper laminar distribution of $\mathrm{CCK}+\mathrm{IN}$ axons in the hippocampus.

\section{Dystroglycan glycosylation is required for CCK+ interneuron axon targeting}

Dystroglycan binds several ligands through extensive glycan chains present on

its extracellular $\alpha-D G$ subunit. The vast majority of cases of dystroglycanopathy are due to mutations in genes required for glycan chain synthesis, rather than Dag1 itself (Bouchet-Séraphin, Vuillaumier-Barrot, and Seta, 2015; Manya and Endo, 2017; Muntoni et al., 2007). Therefore, to determine whether the glycan chains on $\alpha-D G$ are required for $\mathrm{CCK}+\mathrm{IN}$ axon targeting, we examined several mouse lines with varying 
degrees of Dystroglycan glycosylation deficiency. Ispd $d^{L 79^{*} / L 79^{*}}$ mutant mice exhibit a complete loss of Dystroglycan glycosylation and ligand binding capacity due to a nonsense point mutation in an enzyme (also known as Crppa) essential for the extension of sugar chains on Dystroglycan (Praissman et al., 2016; Roscioli et al., 2012; Willer et al., 2012; Wright et al., 2012). Ispd ${ }^{L 79^{*} / L 79^{*}}$ mice display severe brain malformation similar to human patients with the most severe forms of dystroglycanopathy, Walker-Warburg Syndrome (WWS) and Muscle-Eye-Brain Disease (MEB) (Fig. 4A). Examination of the cortex of $\mathrm{PO} / s p d^{L 79^{*} / L 79^{*}}$ mutant mice revealed breakdown of the pial basement membrane and severe disruptions in cortical architecture (Fig. 4B). Immunostaining for deep cortical layer marker CTIP2 revealed severe cortical dysplasia, with ectopic CTIP2+ neurons present in heterotopia characteristic of neuronal migration defects seen in human dystroglycanopathy (Fig. 4C). At PO, $C B_{1} R+$ axons were present in the SR layer of the hippocampus of $I s p d^{L 79^{*} / L 79^{*}}$ mice (Fig. 4D). Unfortunately, Ispd $d^{L 79^{*} / L 79^{*}}$ mutant mice die within hours of birth, likely due to respiratory defects, precluding further analysis of $\mathrm{CB}_{1} \mathrm{R}+$ axons at later developmental time points.

To circumvent the perinatal lethality of $I s p d^{L 79^{*} / L 79^{*}}$ mutants while also eliminating Dystroglycan glycosylation, we took a conditional genetic approach to delete the gene encoding Pomt2 (protein O-mannosyltransferase 2). In mammals, Pomt2 functions in a heterocomplex with Pomt1, and both Pomt1 and Pomt2 are required for the initial Omannosyl linkage for the glycan chains present on Dystroglycan (Manya et al., 2004). In both humans and mice, mutations in POMT1 and POMT2 cause loss of Dystroglycan glycosylation and a severe form of dystroglycanopathy associated with brain 
malformations (Hu et al., 2016; van Reeuwijk et al., 2005; Yanagisawa et al., 2007). In contrast to $/ s p d^{L 79^{*} / L 79^{*}}$ mutants, forebrain-specific Pomt2 conditional knockout mice $\left(E m x 1^{\text {Cre }} ;\right.$ Pomt2 $\left.{ }^{c K O}\right)$ survived until at least P20. Emx1 ${ }^{\text {Cre }} ;$ Pomt $2^{c K O}$ mice had severe cortical migration defects similar to Nestin ${ }^{C r e} ; D a g 1^{c K O}$ and $E m x 1^{C r e} ; D a g 1^{c K O}$ mice (Fig. 5B). To determine whether the hippocampal architecture was affected by loss of Dystroglycan glycosylation, we performed immunostaining for CTIP2 to label excitatory neurons in the CA regions and dentate gyrus. In contrast to the cortex, hippocampal architecture was largely intact, with most hippocampal neurons in the CA regions migrating normally, and the dentate gyrus exhibiting occasional ectopic clusters of neurons (Fig. 5B). We next examined whether $C C K+/ C B_{1} R+I N$ axon targeting was affected in these mice. $\mathrm{CCK}+/ \mathrm{CB}_{1} \mathrm{R}+\mathrm{INs}$ were present in the brains of Emx1 ${ }^{\text {Cre } ; \text { Pomt }}{ }^{c K O}$ mice, but their $\mathrm{CB}_{1} \mathrm{R}+$ axon terminals were noticeably reduced in the PyN cell body layer (SP, stratum pyramidale) of the CA1 and CA3, similar to our

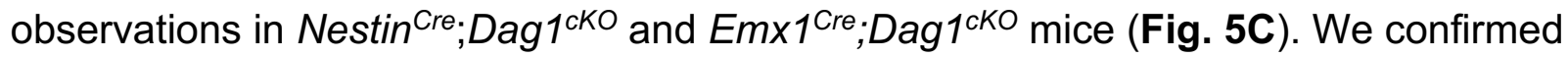
the loss of CCK+ IN axons from the SP with immunostaining for VGLUT3, an independent synaptic marker for CCK+ IN terminals (Fig. 5D). Similar to $\mathrm{CB}_{1} \mathrm{R}$ staining, the density of VGLUT3+ axon terminals was selectively reduced in the SP of Emx1 ${ }^{\text {Cre }} ;$ Pomt $2^{c K O}$ mice. These results conclusively demonstrate that $\mathrm{CCK}+\mathrm{IN}$ innervation of PyNs requires functional glycosylation of Dystroglycan. 
We next examined whether CCK+ IN axon targeting was altered in mice with partial reduction of Dystroglycan glycosylation that model milder forms of dystroglycanopathy. The $\beta$-1,4-glucuronyltransferase B4gat1 (previously known as B3gnt1) is required for Dystroglycan glycan chain synthesis (Buysse et al., 2013; Praissman et al., 2014; Willer et al., 2014). Mice with a homozygous missense mutation in B4gat1 (B4gat1M155T/M155T) exhibit a 65\% reduction in Dystroglycan glycosylation, reduced ligand binding capacity, mild muscular dystrophy, and mild neuronal migration defects present only at the cortical midline (Fig. 6A; Wright et al., 2012). Compared with controls, B4gat1 ${ }^{M 155 T / M 155 T}$ mice exhibited grossly normal cortical layers as shown by immunohistochemical staining for layer marker CUX1 (Fig. 6B). Examination of CCK+ INs in the hippocampus showed that they were present, and there was only a modest reduction of $\mathrm{CB} 1 \mathrm{R}+$ axons in the $\mathrm{SP}$ (Fig. 6C, D).

We next examined mice carrying a homozygous missense mutation in Fkrp (fukutin related protein, Fkrp ${ }^{\text {P48L/P448L }}$ ), that models a human mutation found in a patient with Dystroglycanopathy (Brockington et al., 2001) and have a partial reduction of Dystroglycan glycosylation (Fig. 7A; Chan et al., 2010). Similar to B4gat1M155T/M155T mutant mice, the cortex of $F k r p^{P 448 L / P 448 L}$ mutants exhibited no obvious neuronal migration defects as assessed by CUX1 immunostaining (Fig. 7B). CCK+/CB $1 \mathrm{R}+$ IN axons were also largely unaffected the hippocampus of Fkrp mutant mice (Fig. 7C, D). $\mathrm{CCK}+/ \mathrm{CB}_{1} \mathrm{R}+\mathrm{IN}$ axons in B4gat1 ${ }^{M 155 T / M 155 T}$ and $F k \mathrm{Pp}^{P 448 L / P 448 L}$ mutant mice were also grossly normal in other forebrain brain regions including the cortex, amygdala, and nucleus of the olfactory tract (Fig. S4). Collectively, these results indicate that while $\mathrm{CCK}+/ \mathrm{CB}_{1} \mathrm{R}+\mathrm{IN}$ axon targeting is severely disrupted in mice completely lacking 
glycosylated Dystroglycan $\left(E m \times 1^{C r e} ; P o m t 2^{c K O}\right)$, it is relatively normal in mice with partial loss of Dystroglycan glycosylation (B4gat1 ${ }^{M 155 T / M 155 T}$ and Fkrp ${ }^{\text {P448L/P448L }}$ ).

\section{The cytoplasmic domain of Dystroglycan is not required for CCK+ interneuron axon targeting}

In addition to binding extracellular ligands, Dystroglycan is capable of binding cytoskeletal proteins and transducing signals through its intracellular $\beta$-domain. To determine whether signaling through $\beta-D G$ was required for $C C K+/ C B_{1} R+I N$ axon innervation in the hippocampus, we examined mice lacking the intracellular domain of $\beta$ DG (Dag1 ${ }^{\text {Bcyto/-) }}$ (Fig. 8A, Satz et al., 2009; Satz et al., 2010). Immunostaining for cortical layer marker CUX1 (L2-4) revealed normal brain architecture in Dag1 $1^{\text {cyto/- }}$ mutant mice (Fig. 8B). $C C K+/ C B_{1} R+$ axon distribution in the hippocampus was largely normal and showed intact cell soma targeting of PyNs in SP of CA1, although there was a slight increase in axon density in SO (Fig. 8D). Examination of other forebrain regions in Dag ${ }^{\beta c y t o /-}$ mutant mice revealed abundant $\mathrm{CCK}+\mathrm{IN}$ terminals throughout the cortex, amygdala, and nucleus of the lateral olfactory tract (Fig. S5). Collectively, these results suggest that the intracellular domain of $\beta-D G$ is not required for $C C K+$ IN innervation of PyNs.

\section{DISCUSSION}

Recent work identified a key role for neuronal Dystroglycan in the establishment and function of a subset of inhibitory synapses in the forebrain (Fruh et al., 2016; Miller and Wright, 2021). Deletion of Dag1 selectively from pyramidal neurons 
$\left(N E X^{C r e} ; D a g 1^{c K O}\right)$ led to a nearly complete loss of $C C K+/ C B{ }_{1} R+I N s$ that was observed during the first few postnatal weeks. In this study, we sought to better understand how $\mathrm{CCK}+/ \mathrm{CB}_{1} \mathrm{R}+\mathrm{IN}$ development is affected in mouse models that more accurately reflect dystroglycanopathy, where Dystroglycan function is lost more broadly throughout the CNS (Fig. 1). Using two distinct models that delete Dag1 throughout the developing forebrain (Nestin ${ }^{C r e} ;$ Dag $1^{c K O}$ and $\left.E m \times 1^{C r e} ; D_{a g} 1^{c K O}\right)$, we found that $C C K+/ C B 1 R+I N s$ were present, but the laminar organization of their axon terminals and their ability to form basket synapses onto pyramidal neuron cell bodies in the hippocampus was impaired (Fig 2). The inability of $\mathrm{CCK}+/ \mathrm{CB}_{1} \mathrm{R}+$ axon terminals to concentrate in cell body layers began to manifest during the first postnatal week, when dynamic changes in laminar innervation by $\mathrm{CCK}+/ \mathrm{CB}_{1} \mathrm{R}+$ axons normally occur (Fig. 3). We also found that the ability of Dystroglycan to regulate $C C K+/ C B_{1} R+I N$ innervation requires its glycosylation, as $E m \times 1^{\mathrm{Cre}} ;$ Pomt $2^{c K O}$ mice showed an identical phenotype (Fig. 5). In contrast, mice with a partial loss in glycosylation that model a milder form of dystroglycanopathy (B4gat1 ${ }^{M 155 T / M 155 T}$ and Fkrp ${ }^{P 448 L / P 448 L}$ ) had relatively normal $\mathrm{CCK}+/ \mathrm{CB}_{1} \mathrm{R}+\mathrm{IN}$ innervation (Figs. 6 and 7). These results suggest that while Dystroglycan glycosylation is essential for $C C K+/ C B_{1} R+I N$ development, the residual Dystroglycan function present in B4gat1 $1^{M 155 T / M 155 T}$ and Fkrp ${ }^{P 448 L / P 448 L}$ mutants is sufficient for most aspects of brain development and for $C C K+/ C B_{1} R+$ axon targeting to proceed normally. Finally, using Dag $1^{\beta c y t o /-}$ mutants, we showed that signaling through the intracellular domain of Dystroglycan is not required for normal $C C K+/ C B_{1} R+I N$ development and innervation (see Table 1 for summary of phenotypes). 
Table 1. Summary of phenotypes

\begin{tabular}{|c|c|c|c|c|c|}
\hline Mouse line & $\begin{array}{l}\text { Dystroglycan } \\
\text { status }\end{array}$ & $\begin{array}{l}\text { Cells/brain } \\
\text { regions } \\
\text { affected }\end{array}$ & $\begin{array}{l}\text { Axon } \\
\text { targeting } \\
\text { defect }\end{array}$ & $\begin{array}{l}\text { CB1R } \\
\text { axons } \\
\text { present }\end{array}$ & $\begin{array}{l}\text { *Phenotype } \\
\text { severity }\end{array}$ \\
\hline${ }^{\#} N e x^{C r e}-D a g 1^{c K O}$ & No DG & $\begin{array}{l}\text { Excitatory } \\
\text { neurons }\end{array}$ & $\mathrm{Y}$ & $\mathrm{N}$ & +++++ \\
\hline$E m \times 1^{C r e}-D a g 1^{c K O}$ & No DG & $\begin{array}{l}\text { Forebrain } \\
\text { excitatory } \\
\text { neurons, glia }\end{array}$ & $\mathrm{Y}$ & $\mathrm{Y}$ & ++++ \\
\hline Nestin ${ }^{C r e}-D a g 1^{c K O}$ & No DG & CNS & $Y$ & $\mathrm{Y}$ & +++ \\
\hline Emx $1^{\text {Cre }}-$ Pomt $2^{c K O}$ & $\begin{array}{l}\text { No glycosylated } \\
\text { DG }\end{array}$ & $\begin{array}{l}\text { Forebrain } \\
\text { excitatory } \\
\text { neurons, glia }\end{array}$ & $\mathrm{Y}$ & $\mathrm{Y}$ & ++++ \\
\hline${ }_{\text {reERT2 }}^{\# D a g} 1^{i c K o} ; C a m k 2 a^{C}$ & $\begin{array}{l}\text { No DG in adult } \\
\text { excitatory } \\
\text { neurons }\end{array}$ & $\begin{array}{l}\text { Excitatory } \\
\text { neurons } \\
\text { (adult) }\end{array}$ & $\mathrm{N}$ & $\mathrm{Y}$ & - \\
\hline$D a g 1^{\beta c y t o /-}$ & $\begin{array}{l}\text { Deletion of } \beta-D G \\
\text { intracellular } \\
\text { domain }\end{array}$ & All & $\mathrm{Y}$ & $\mathrm{Y}$ & + \\
\hline$I s p d^{L 79^{*}}(\mathrm{P} 0)$ & $\begin{array}{l}\text { Absence of } \alpha-D G \\
\text { glycosylation }\end{array}$ & All & $\mathrm{N} / \mathrm{A}$ & $\mathrm{Y}$ & $\mathrm{N} / \mathrm{A}$ \\
\hline$F k r p^{P 448 L}$ & $\begin{array}{l}\alpha-D G \\
\text { hypoglycosylation }\end{array}$ & All & $\mathrm{Y}$ & $\mathrm{Y}$ & + \\
\hline B4gat1 ${ }^{M 155 T}$ & $\begin{array}{l}\alpha-D G \\
\text { hypoglycosylation }\end{array}$ & All & $\mathrm{Y}$ & $\mathrm{Y}$ & + \\
\hline
\end{tabular}

Table 1. *Phenotypic severity scale ranges from mild $(+)$ to severe (+++++). No phenotype is denoted by (-). " Data from Miller and Wright, 2021.

\section{What is the function of Dystroglycan in CCK+ interneuron development?}

What is the precise role of Dystroglycan in the development of CCK+

interneurons and their synapses? Synaptogenesis requires multiple distinct steps: (1)

synaptic partner recognition (2) recruitment and assembly of core inhibitory/excitatory

synaptic machinery (3) differentiation and maturation of synaptic identity, and (4)

synaptic maintenance (Sudhof, 2018). Based on data from this study and previous work

from our group and others, mice lacking Dystroglycan exhibit defects in the

development of $\mathrm{CCK}+\mathrm{INs}$ at the earliest time point they (or their $\mathrm{CB} 1 \mathrm{R}+$ axons) can be

reliably identified (P0-P5). This period precedes the peak of inhibitory synapse 
formation (P9), suggesting that Dystroglycan functions at early stages of synaptogenesis such as synaptic partner recognition (Favuzzi et al., 2019). Early studies characterizing the development of $\mathrm{CCK}+\mathrm{INs}$ in the rat brain demonstrated that $\mathrm{CCK}+$ INs are capable of forming synaptic connections at early postnatal ages (P3-4) (Morozov and Freund, 2003). Later work showed that putative CCK+ INs were capable of firing action potentials at late embryonic ages (Calvigioni et al., 2017). Although the peak of inhibitory synapse formation occurs around P9 using general inhibitory synapse markers (VGAT), individual IN subtypes may establish synapses onto their targets at different times. For instance, chandelier cells begin innervating PyN axon initial segments around P12 and complete synaptogenesis by P28 (Tai et al., 2019). Unfortunately, determining the precise onset of synapse targeting and formation for most IN subtypes, including CCK+ INs, is often limited by a lack of genetic tools for visualizing and manipulating IN subtypes during developmental stages.

\section{Role of the Dystrophin-Glycoprotein Complex (DGC) in CCK+ IN development}

In brain and muscle tissue, Dystroglycan forms a complex with Dystrophin and several other proteins, collectively known as the Dystrophin Glycoprotein Complex (DGC). Like Dystroglycan, Dystrophin is also expressed throughout the forebrain and has been associated with inhibitory synapses in multiple brain regions (Knuesel et al., 1999). Patients with mutations in Dystrophin develop Duchenne Muscular Dystrophy (DMD), and frequently exhibit cognitive impairments in the absence of brain malformations, suggesting a general role for the DGC in synapse development or function (Jagadha and Becker, 1988; Moizard et al., 2000; Naidoo and Anthony, 2020). 
Interestingly, a mouse model of DMD lacking all Dystrophin isoforms $(m d x)$ exhibits defects in CCK+ IN synapse development and abnormal $\mathrm{CB}_{1} \mathrm{R} / \mathrm{VGLUT3}$ innervation in the hippocampus, similar to the results we observed in Dag $1^{c K O}$ and Pomt2 ${ }^{c K O}$ mice in this study (Krasowska et al., 2014). A better understanding the relationship between Dystroglycan and Dystrophin at inhibitory synapses in the brain will be important for developing therapies for dystroglycanopathy and DMD.

The impairment in CCK+ IN development suggests a trans-synaptic role for Dystroglycan, although its pre-synaptic binding partners remain unknown. Our data in Emx $1^{\text {Cre }}$;Pomt $2^{c K O}$ mice point to a critical role for the glycan chains on Dystroglycan mediating this binding. All of the known proteins that bind to the glycan chains present on Dystroglycan do so through at least one Laminin G (LG) domain. Potential binding partners include presynaptic Neurexins, which contain multiple LG domains (Sugita et al., 2001). The Neurexin (NRXN1-3) family of synaptic cell-adhesion molecules are highly alternatively spliced, and specific isoforms are differentially expressed by CCK+ and PV+ interneurons (Ullrich et al., 1995; Fucillo et al., 2015). $\alpha$-DG biochemically interacts with particular splice isoforms of Neurexins present in CCK+ INs (Sugita et al., 2001; Boucard et al., 2005; Reissner et al., 2014; Fucillo, et al., 2015). A recent study conditionally deleting all three Neurexins in PV and SOM interneurons found only a modest decrease of inhibitory synapses in the cortex, indicating that Neurexins may play a more important role in synapse function than synapse formation and maintenance (Chen et al., 2017). However, whether Neurexins are required for CCK+ IN development has not been examined, leaving open the possibility that Neurexins interact with Dystroglycan to regulate CCK+ IN synapse formation. Alternatively, other 
pre-synaptic LG domain containing cell adhesion proteins could interact with

Dystroglycan to form a trans-synaptic adhesion complex.

\section{What are the consequences of altered CCK+ IN development in dystroglycanopathy?}

Recently, CCK+ INs have been implicated in a wide variety of important neural circuit functions that support diverse forms of cognition in mice, including spatial coding, fear extinction, and working memory (Busquets-Garcia et al., 2018; Del Pino et al., 2017; Nguyen et al., 2020; Rovira-Esteban et al., 2019; Veres et al., 2017; Whissell et al., 2019). CCK+ INs play a role in the expression of long-term potentiation (LTP) in the hippocampus (Jensen et al., 2021), and mice lacking Dystroglycan from PyNs (Nex ${ }^{\mathrm{Cre}}$ ) also exhibit defects in (LTP) (Satz et al., 2010). These mice also lack most $\mathrm{CB}_{1} \mathrm{R}$ axon terminals, raising the possibility that reduced $\mathrm{CB}_{1} \mathrm{R}$ function contributes to LTP defects (Miller and Wright, 2021). Indeed, conditional deletion of Cnr1 from CCK+ INs also leads to defects in LTP (Monory et al., 2015). Collectively, these results suggest that $\mathrm{CCK}+\mathrm{INs}$ and their $\mathrm{CB}_{1} \mathrm{R}+$ axons are important for multiple forms of memory in mice.

Mouse models recapitulate many key neuroanatomical defects and pathological mechanisms in human dystroglycanopathy. What can these results in mouse models tell us about the role of Dystroglycan in regulating inhibitory synapse development and/or function in patients with dystroglycanopathy? Cognitive impairments are frequently observed in human patients with dystroglycanopathy and Duchenne Muscular Dystrophy (Clement et al., 2008). Whether impairments in CCK+ IN development or function contribute to neurological symptoms in dystroglycanopathy is 
unknown. In human fetal brains, $\mathrm{CB}_{1} \mathrm{R}+$ axons from putative $\mathrm{CCK}+\mathrm{INs}$ can be detected as early as gestational week 19 and are highly concentrated in limbic regions of the brain including the cortex, hippocampus, and amygdala (Glass et al., 1997; Mato et al., 2003; Wang et al., 2003). Similar to rodents, CCK+ IN axon terminals undergo dramatic laminar redistribution during development, ultimately forming characteristic perisomatic basket synapses onto excitatory neuron cell bodies (Eggan et al., 2007; Eggan et al., 2010a; Eggan et al., 2010b). Currently, it is unknown whether specific populations of interneurons such as CCK+ INs develop properly in the brains of patients with dystroglycanopathy, and this will be important to determine for future therapeutic efforts.

\section{Therapeutic implications for CNS defects in dystroglycanopathy}

Defining where, when, and how Dystroglycan functions during development of the nervous system is critical for determining therapeutic strategies for treating dystroglycanopathy. Conditional knockouts of Dag1 have been essential for unraveling its cell type specific functions in neuroepithelial cells, neurons, astrocytes, oligodendrocytes. They have also revealed that many of the major neuroanatomical defects seen in severe dystroglycanopathy emerge early in neurodevelopment. One open question is whether restoring Dystroglycan function via gene therapy or pharmacological intervention can rescue synaptic connections or synapse function in the context of structural brain abnormalities. It is unlikely that structural brain defects will be amenable to correction with gene therapy due to the role Dystroglycan plays at the earliest stages of brain development. However, synaptogenesis is one of the final stages in the development of functional neural circuits, raising the possibility that 
synaptic defects may be correctable (Liu et al., 2012). Encouragingly, postnatal gene therapy restored Dystroglycan glycosylation and rescued behavioral impairments in a mouse model of dystroglycanopathy with brain malformations (Hu et al., 2016).

Furthermore, mouse models of dystroglycanopathy have revealed that residual levels of Dystroglycan glycosylation may be sufficient to prevent the development of muscular dystrophy symptoms (Kanagawa et al., 2009). These findings are consistent with our observations in the nervous system in this study, as mice with a partial reduction in glycosylation (B4gat1M155T/M155T and Fkrp ${ }^{\text {P448L/P448L) }}$ ) have structurally normal brains and relatively normal $\mathrm{CCK}+/ \mathrm{CB}_{1} \mathrm{R}+\mathrm{IN}$ innervation. Partial restoration of Dystroglycan glycosylation in muscle via AAV-mediated delivery of FKRP or ribitol supplementation ameliorates disease severity, suggesting that similar approaches may also improve CNS function (Awano et al., 2015; Cataldi et al., 2018, 2020; Qiao et al., 2014). However, due to the genetic heterogeneity underlying hypoglycosylation in dystroglycanopathy, alternative strategies have been proposed that bypass the need for restoring Dystroglycan glycosylation altogether (Gumlaw et al., 2020). In sum, understanding Dystroglycan's roles in brain development will allow for more effective gene therapies aimed at restoring cognitive function in human patients with dystroglycanopathy.

\section{CONCLUSION}

We demonstrate that Dystroglycan is critical for the postnatal development of CCK+ interneuron axon targeting in the hippocampus of mouse models of severe dystroglycanopathy. Functional glycosylation of Dystroglycan is essential for its synaptic 
organizing function, while its intracellular domain appears to play a minor role. Mice with a partial reduction in glycosylation have relatively normal CCK+ axon targeting, suggesting that even partial restoration of glycosylation may have some therapeutic benefit. These findings suggest that CCK+ interneuron axon targeting defects may contribute to cognitive impairments in dystroglycanopathy.

\section{MATERIALS AND METHODS}

\section{Animal husbandry}

All animals were housed and cared for by the Department of Comparative Medicine (DCM) at Oregon Health and Science University (OHSU), an AAALAC-accredited institution. Animal procedures were approved by OHSU Institutional Animal Care and Use Committee (Protocol \# IS00000539), adhered to the NIH Guide for the care and use of laboratory animals, and provided with 24 hour veterinary care. Animal facilities are regulated for temperature and humidity and maintained on a 12 hour light-dark cycle and were provided food and water ad libitum. Animals older than postnatal day 6 (P6) were euthanized by administration of $\mathrm{CO}_{2}$, animals $<\mathrm{P} 6$ were euthanized by rapid decapitation.

\section{Mouse strains and genotyping}

The day of birth was designated postnatal day 0 (P0). Ages of mice used for each analysis are indicated in the figure and figure legends. Mouse strains used in this study have been previously described and were obtained from Jackson Labs, unless otherwise indicated (Table 2): Dystroglycan conditional mice Dag1Flox (JAX \#009652; 
Cohn et al., 2002; Moore et al., 2010), Dag1/- (JAX \#006836; Williamson et al., 1997), $\operatorname{Dag}^{\text {Bcyto }}$ (Satz et al., 2009), Emx1/RES-Cre (JAX \#005628; Gorski et al., 2002; Guo et al.,

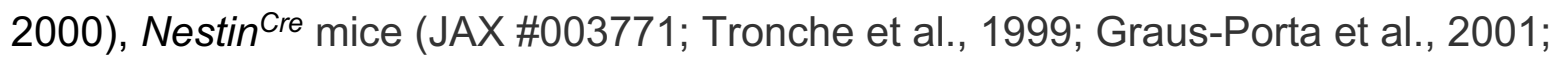

Dubois et al., 2006). The generation and genotyping of mutant $B 4 g a t 1^{M 155 T}$ and $I s p d^{L 79^{*}}$ mice was previously described (Wright et al., 2012). The R26 LSL-H2B-mCherry reporter mouse (JAX \#023139; Peron et al., 2015) was used to conditionally express red fluorescent protein in nuclei upon Cre-mediated deletion of a floxed STOP cassette. All mice were maintained on a C57BL/6 background. To generate control and Dystroglycan conditional knockout mice, Nestin ${ }^{\mathrm{Cre} /+} ; \mathrm{Dag} 1^{+/-}$or $\mathrm{Em} \times 1^{\mathrm{Cre} /+} ; \mathrm{Dag} 1^{+/-}$mice were bred with Dystroglycan homozygous floxed mice (Dag $\left.1^{\text {Flox/Flox }}\right)$. Cre positive age-matched littermates were used as controls. Genomic DNA extracted from toe or tail samples (Quanta BioSciences) was used to genotype animals. The presence of the Cre allele in Nestin ${ }^{\mathrm{Cre}}$ and $\mathrm{Em} \times 1^{\mathrm{Cre}}$ mice was detected using generic Cre primers (JAX). Floxed alleles were detected as previously described (Michele et al., 2002).

\section{Table 2. Mouse strains}

\begin{tabular}{|c|c|c|c|}
\hline Common name & Strain name & Reference & Stock \# \\
\hline $\operatorname{Dag} 1^{-/-}$ & B6.129-Dag1 $1^{\text {tm1Kcam } / J}$ & Williamson et al., 1997 & 006836 \\
\hline $\operatorname{Dag} 1^{\text {Flox }}$ & B6.129(Cg)-Dag $1^{\text {tm2.1Kcam } / J}$ & Cohn et al., 2002 & 009652 \\
\hline Dag1 $1^{\beta c y t o}$ & $\mathrm{~N} / \mathrm{A}$ & Satz et al., 2009 & $\mathrm{~N} / \mathrm{A}$ \\
\hline$I s p d^{L 79^{*}}$ & C3.B6-Ispd $d^{m 1 D d g} / J$ & Wright et al., 2012 & 022019 \\
\hline B4gat1 ${ }^{M 155 T}$ & $B 6(C 3)-B 4 g a t 1^{m 1 D d g} / J$ & Wright et al., 2012 & 022018 \\
\hline Fkrp ${ }^{P 448 L}$ & C57BL/6NJ-Fkrp ${ }^{e m 1 L g m d} / J$ & Chan et al., 2010 & 034659 \\
\hline$R 26^{\text {LSL-H2B-mCherry }}$ & B6.Gt(ROSA)26Sor ${ }^{t m 1.1 K s v o}$ & Peron, et al., 2015 & 023139 \\
\hline Emx $1^{\text {Cre }}$ & B6.129S2-Emx1 $1^{\operatorname{tm1}(\mathrm{cre}) K r j} / J$ & Gorski et al., 2002 & 005628 \\
\hline Nestin ${ }^{\text {Cre }}$ & B6.Cg-Tg(Nes-cre $)^{1 / K I n} / J$ & Tronche et al., 1999 & 003771 \\
\hline
\end{tabular}

\section{Perfusions and tissue preparation}


Brains from mice younger than P15 were dissected and drop fixed in $5 \mathrm{mls}$ of $4 \%$ paraformaldehyde (PFA) in phosphate buffered saline (PBS) overnight for 18-24 hrs at 4 degrees $\mathrm{C}$. Mice P15 and older were deeply anesthetized using $\mathrm{CO} 2$ and transcardially perfused with ice cold $0.1 \mathrm{M}$ PBS for two minutes to clear blood from the brain, followed by $15 \mathrm{mls}$ of ice cold 4\% PFA in PBS. After perfusion, brains were dissected and post-fixed in 4\% PFA for two or 24 hours. Brains were rinsed with PBS, embedded in 4\% low-melt agarose (Fisher: Cat\# 16520100), and sectioned at 40 um using a vibratome (VT1200S, Leica Microsystems Inc., Buffalo Grove, IL) into 24-well plates containing $1 \mathrm{ml}$ of $0.1 \mathrm{M}$ PBS.

\section{Immunohistochemistry}

Single and multiple immunofluorescence detection of antigens was performed as follows: Free-floating vibratome sections $(40 \mu \mathrm{m})$ were briefly rinsed with PBS, then blocked for $1 \mathrm{hr}$ in PBS containing $0.2 \%$ Triton-X (PBST) plus 10\% normal donkey serum. Sections were incubated with primary antibodies (Table 3) diluted in PBST at 4 degrees C overnight (18-24 hrs). For staining of Dystroglycan synaptic puncta, an antigen retrieval step was performed prior to incubation in primary antibody. Briefly, sections were incubated in sodium citrate solution for $15 \mathrm{~min}$ at 95 degrees in a water bath. Following incubation in primary antibody, sections were rinsed briefly with PBS then washed with PBST three times for 20 min each. Sections were then incubated with a cocktail of secondary antibodies (1:1000, Alexa Fluor 488, 546, 647; Fisher) in PBST for $90 \mathrm{~min}$ at room temperature. Sections were washed with PBS three times for $20 \mathrm{~min}$ each and counterstained with Hoescht 33342 (Life Technologies, Cat\# H3570) for 10 
min to visualize nuclei. Finally, sections were mounted on slides using Fluoromount-G

(Fisher; SouthernBiotech) and sealed using nail polish.

Table 3. Primary antibodies used for immunohistochemistry

\begin{tabular}{llllll}
\hline Target & Host & Dilution & Source & Catalog \# & RRID \\
\hline a-Dystroglycan & Mouse & $1: 200$ & Millipore & 05-593 & AB_309828 \\
(IIH6C4) & Guinea pig & $1: 2000$ & Synaptic Systems & $258-104$ & AB_2661870 \\
CB1R & Rat & $1: 500$ & Abcam & ab18465 & AB_2064130 \\
Ctip2 & Rabbit & $1: 250$ & Santa Cruz Biotech & sc-13024 & AB_2261231 \\
Cux1 & Chicken & $1: 1000$ & Abcam & 13970 & AB_300798 \\
GFP & Rabbit & $1: 1000$ & Sigma & L9393 & AB_477163 \\
Laminin & Rabbit & $1: 2000$ & Sigma & HPA023629 & AB1848014 \\
NECAB1 & Mouse & $1: 250$ & Millipore & MAB377 & AB_2298772 \\
NeuN & Rabbit & $1: 2000$ & Peninsula Labs & T-4103 & AB_518614 \\
Somatostatin & Rabbit & $1: 2000$ & Synaptic Systems & $135-203$ & AB_887886 \\
VGlut3 & Rabbit & $1: 1000$ & ImmunoStar & 20077 & AB_572270 \\
VIP & & & & &
\end{tabular}

\section{Microscopy}

Imaging was performed on a Zeiss Axio Imager M2 fluorescence upright microscope equipped with an Apotome.2 module for structured illumination microscopy. The microscope uses a metal halide light source (HXP 200 C), Axiocam 506 mono camera, and 10X/0.3 NA EC Plan-Neofluar, 20X/0.8 NA Plan-Apochromat objectives. Z-stack images were acquired and processed as maximum projection images using Zeiss Zen Imaging software, and analyzed offline in ImageJ/FIJI (Schindelin et al., 2012). Images used for quantification between genotypes were acquired using the same exposure times. Brightness and contrast were adjusted in FIJI to improve visibility of images for publication. Figures were composed in Adobe Illustrator CS6 (Adobe Systems).

\section{Quantification}


Quantification of $\mathrm{CB}_{1} \mathrm{R}$ terminals in the hippocampus was performed on $5 \mu \mathrm{m}$ z-stacks acquired using a 20X objective. 10-12 images of the CA1 were acquired from 5-6 sections per animal (technical replicates), and at least three animals per genotype (biological replicates) were used for analysis. Sections were taken from equivalent rostro-caudal positions including the dorsal hippocampus (Bregma between -1.48 to $1.94 \mathrm{~mm}$ ) using coordinates from the mouse brain atlas (Franklin and Paxinos, 1997). All images used for quantification were processed identically. Briefly, background subtraction (Rolling ball radius $=50$ ) and mean filtering (Smooth function in FIJI) were applied to each image to enhance the detection of $\mathrm{CB}_{1} \mathrm{R}$ terminals by thresholding. To measure $\mathrm{CB}_{1} \mathrm{R}$ signal, a threshold was manually set and applied equally across images to detect only $\mathrm{CB}_{1} \mathrm{R}$ signal. Hoechst signal in the SP (CA regions) were used to align the placement of the ROI in the SO, SP, and SR. Raw integrated density values were averaged across all images for each animal and hippocampal layer, and normalized to the mean intensity of the control group (set to $100 \%$ for each ROI).

\section{Statistical analysis}

All phenotypic analyses were conducted using tissue collected from at least three mice per genotype from at least two independent litters. The number of mice used for each analysis (" $n$ ") are indicated in the text and figure legends. No specific power analyses were performed, but sample sizes were similar to our previous work and other published literature (Wright et al., 2012; Clements et al., 2017, 2018; Lindenmaier et al., 2019). Phenotypes were indistinguishable between male and female mice and were analyzed together. In many cases, highly penetrant phenotypes revealed the genotypes of the 
mice and no blinding could be performed. For comparisons between two groups, significance was determined using a two-tailed Students t-test. Statistical significance was set at alpha $=0.05(P<0.05)$ and data presented as means \pm s.e.m. All statistical analyses were performed in Prism Graphpad (San Diego, CA). 

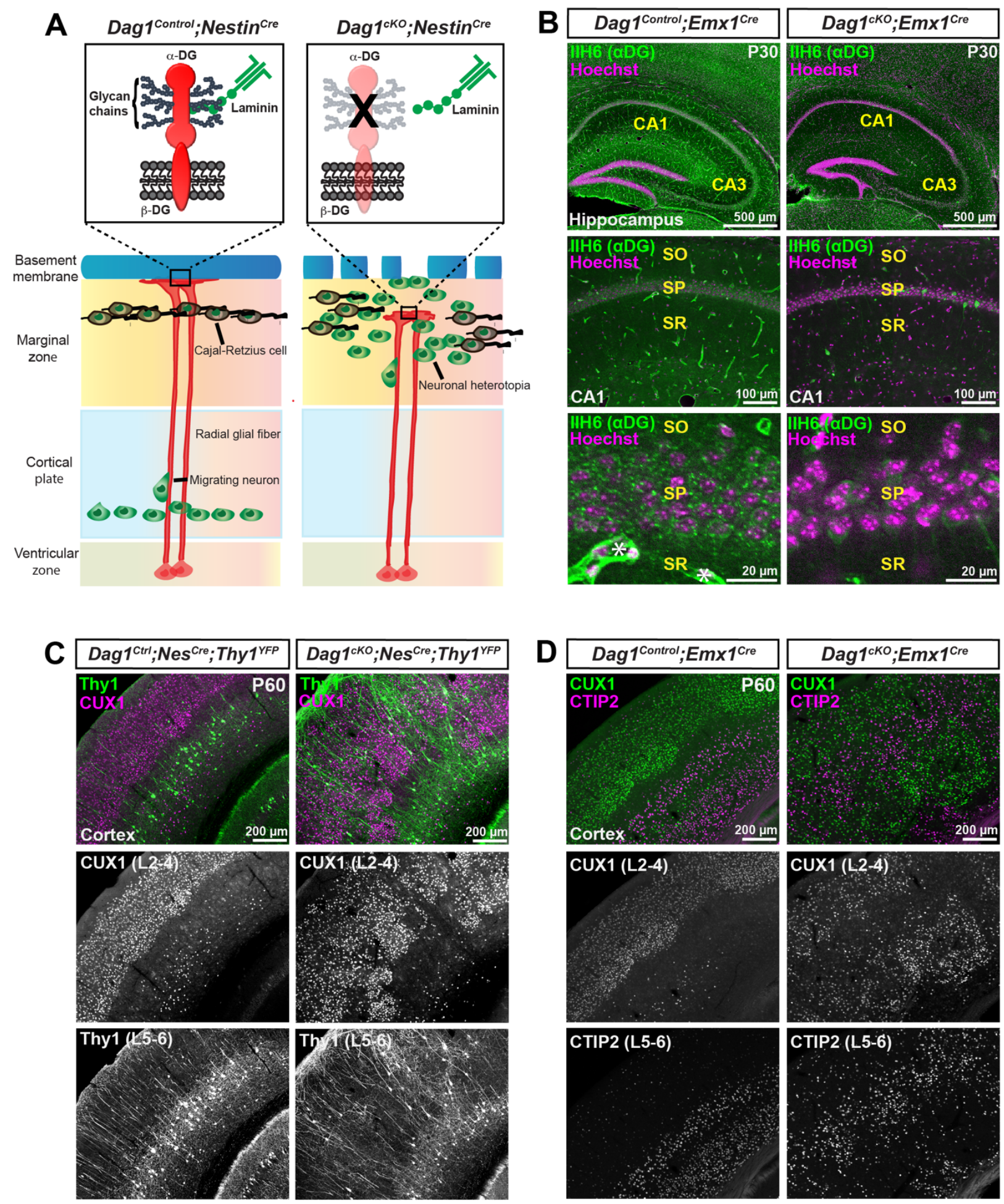

Figure 1. Central nervous system deletion of Dystroglycan leads to cortical migration defects resembling severe dystroglycanopathy. (A) Schematic of Dystroglycan showing glycan chains on the extracellular alpha subunit $(\alpha-D G)$, and the transmembrane beta subunit ( $\beta-D G)$. Dystroglycan is localized to radial glial endfeet where it binds laminin at the cortical surface. Deletion of Dystroglycan from the 
neuroepithelium (Dag1 $\left.{ }^{\text {KKO}} ; \mathrm{Nestin}^{\mathrm{Cre}}\right)$ leads to breaches in the basement membrane and neuronal heterotopia (ectopic cortical neurons). (B) Coronal sections from P30 Dag ${ }^{\text {Control; }}$ Em $m 1^{\text {Cre }}$ mice (left) immunostained for Dystroglycan (IIH6, green) shows abundant staining of blood vessels in the cortex and hippocampus (white asterisks,

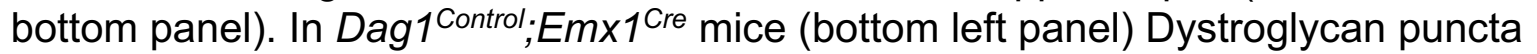
(green) are found on cell bodies (Hoechst, magenta) in the pyramidal cell body layer

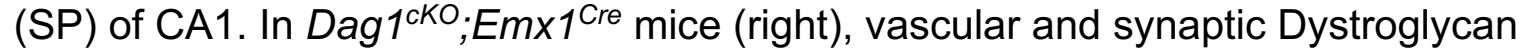
staining are absent from the cortex and hippocampus. CA1 layers: SO, stratum oriens; SP, stratum pyramidale; SR, stratum radiatum. (C) Sections from Dag ${ }^{\text {Control;NNestin }}{ }^{\text {Cre }}$ (left) and Dag $1^{\text {CKO} ; N e s t i n}{ }^{\text {Cre }}$ mice (right) crossed with a Thy $1^{\text {YFP }}$ reporter mouse to sparsely label layer 5-6 pyramidal neurons (green). CUX1 (magenta) labels layer 2-4 pyramidal neurons. (D) Coronal sections from Dag $1^{\text {Control }}$;Em $\times 1^{\text {Cre }}$ (left) and $D a g 1^{c K O} ; E m \times 1^{C r e}$ mice (right) immunostained for cortical layer markers CUX1 (green, L2-4) and CTIP2 (magenta, L5-6). Single channel images (gray) are shown below. 

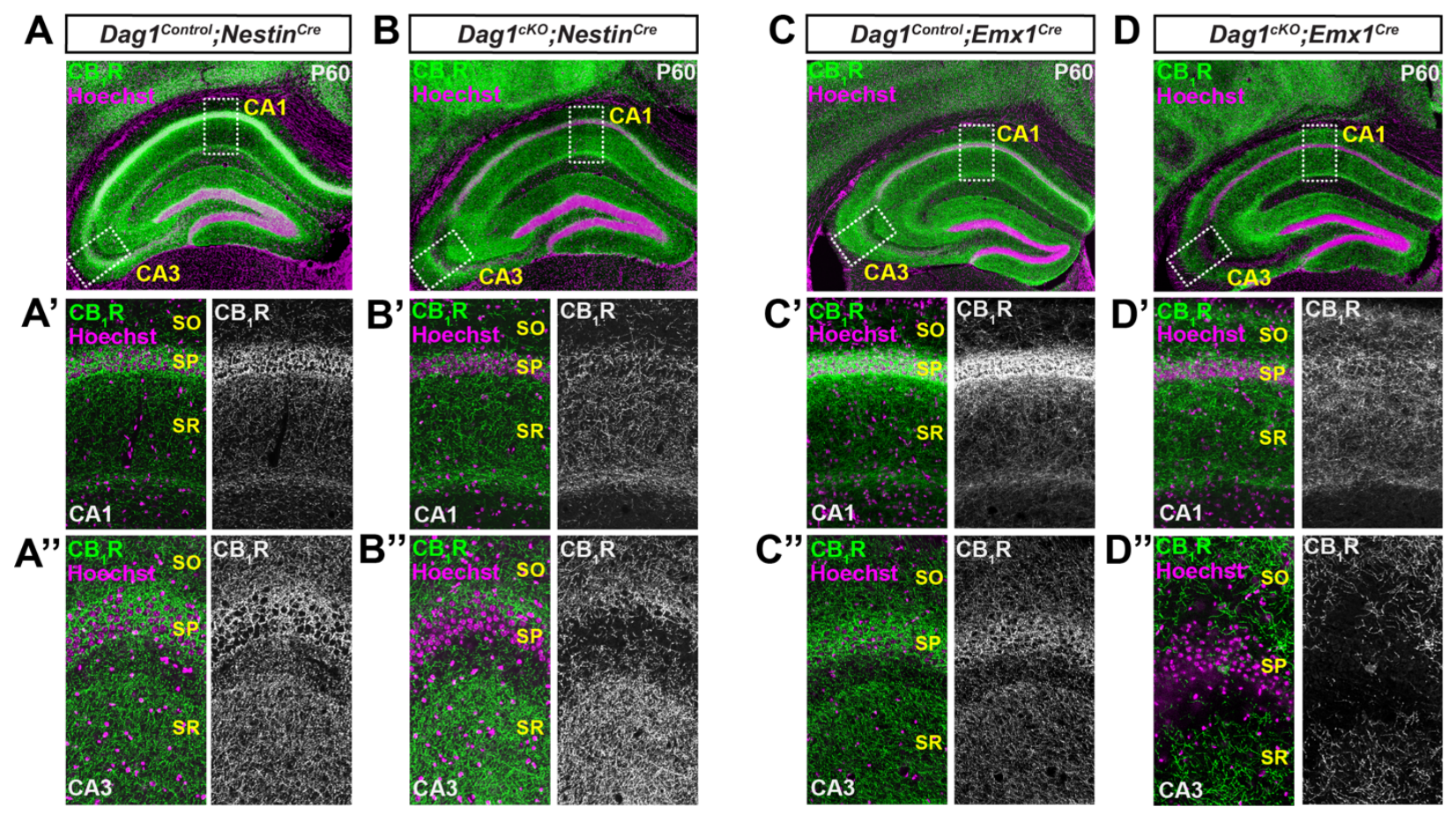

Figure 2. Dystroglycan is required for $\mathrm{CCK}+$ interneuron axon targeting of pyramidal neurons. (A, B) Immunostaining for $\mathrm{CB}_{1} \mathrm{R}$ (green) labels $\mathrm{CCK}$ interneuron axon terminals in the hippocampus of P60 Dag $1^{\text {Control; } N e s t i n}{ }^{\text {Cre }}(\mathbf{A})$ and Dag ${ }^{\text {CKO; }}$ Nestin ${ }^{\text {Cre mice (B). In Dag }{ }^{\text {Control; }} \text { Nestin }}{ }^{\text {Cre }}$ mice (A), $\mathrm{CB}_{1} \mathrm{R}+$ axon terminals are concentrated in the pyramidal cell body layer (SP) of CA1 (A') and CA3 (A'). In Dag ${ }^{1 K O}$;Nestin ${ }^{C r e}$ mice $(B), C_{1} R+$ axon terminal density was reduced in the pyramidal cell body layer (SP) of CA1 (B') and CA3 (B')). (C, D) Immunostaining for $\mathrm{CB}_{1} \mathrm{R}$ (green) in the hippocampus of P60 Dag $1^{\text {Control }}$ Em $m \times 1^{\text {Cre }}$ (C) and Dag $1^{\text {CKO }}$;Em $x 1^{\text {Cre }}$ mice (D) shows reduced $\mathrm{CB}_{1} \mathrm{R}+$ axon terminal density in the SP of CA1 (D') and CA3 (D')

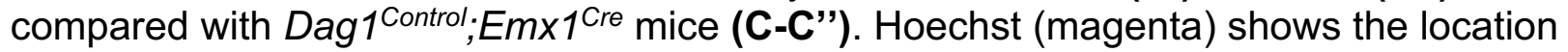
of the SP. Single channel $\mathrm{CB}_{1} \mathrm{R}$ images (gray) are shown to the right. 

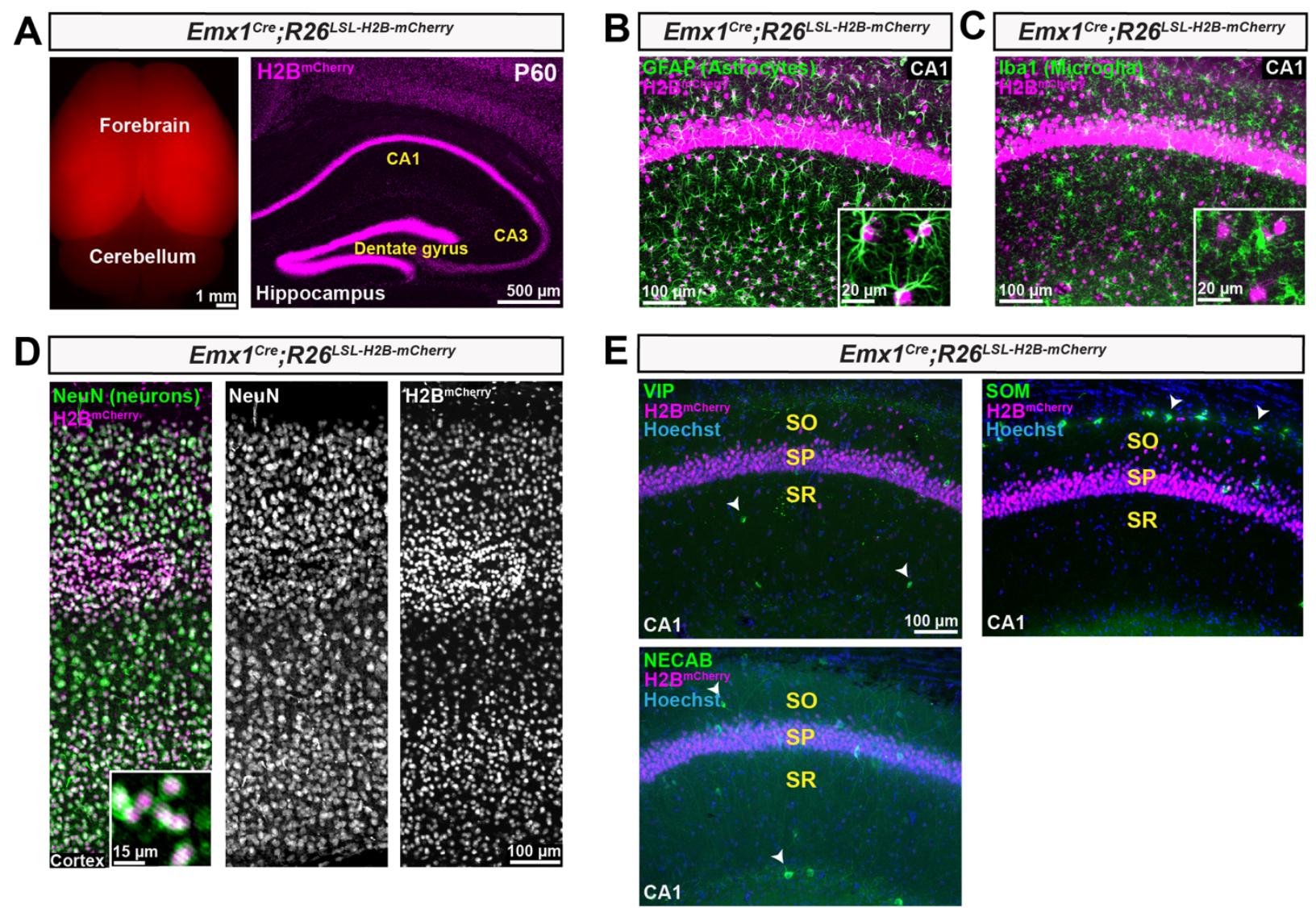

Figure S1. Emx $1^{\text {Cre }}$ drives recombination in forebrain excitatory neurons and astrocytes, but not interneurons or microglia. (A) Left; endogenous red fluorescence in the forebrain of P60 Emx $1^{\text {Cre }} ; R 26^{L S L}$-H2B-mCherry reporter mice. Right; coronal section of the forebrain from $E m \times 1^{C r e} ; R 26^{L S L-H 2 B-m C h e r r y}$ mice showing robust nuclear mCherry signal (magenta) in the cortex and hippocampus. (B-D) mCherry+ nuclei overlap with markers of multiple cell types in the brain including astrocytes (GFAP, green) (B), microglia (Iba1, green) (C), and neurons (NeuN, green) (D). Insets show enlarged images of mCherry+ nuclei overlapping with cell type markers. (E) mCherry+ nuclei did not overlap with markers for interneuron cell bodies (white arrowheads). CA1 layers: $\mathrm{SO}$, stratum oriens; SP, stratum pyramidale; SR, stratum radiatum. 

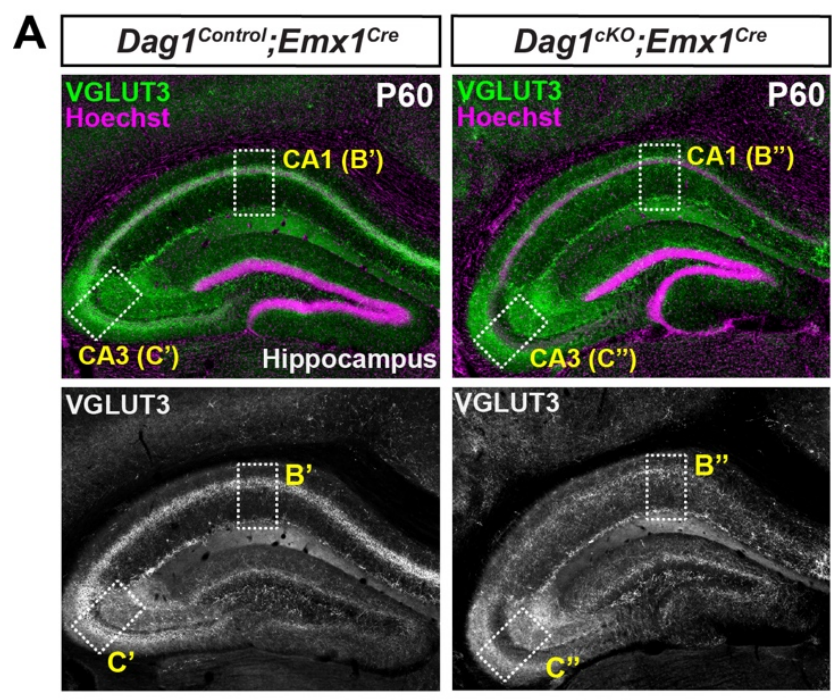
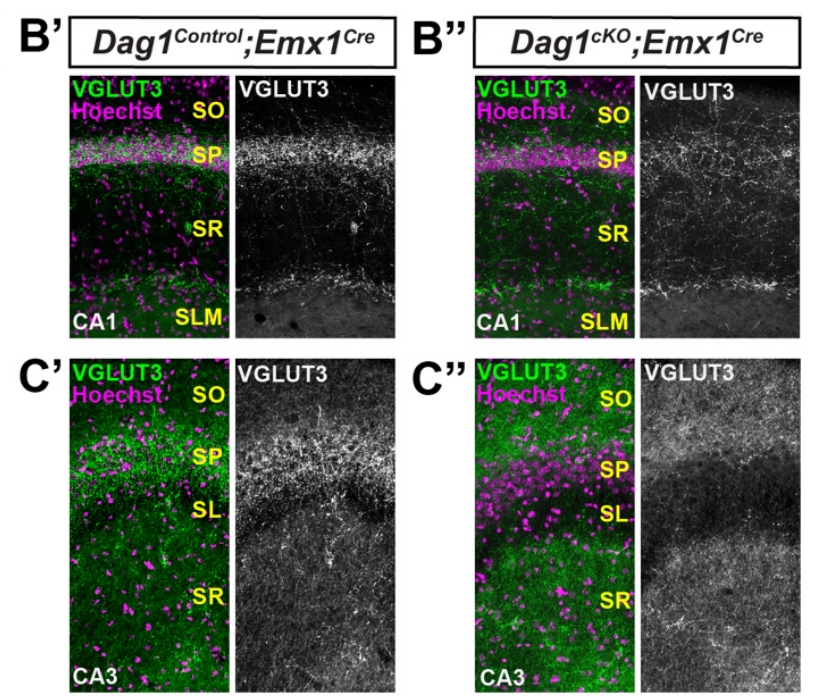

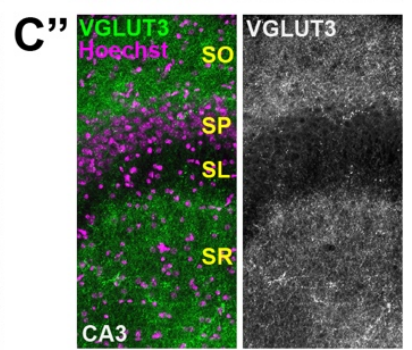

Figure S2. Abnormal distribution of VGLUT3+ terminals in Dag1cKo;Emx1 ${ }^{\text {Cre }}$ mice. (A) Immunostaining for VGLUT3 (green) in the hippocampus of P60 Dag $1^{\text {Control; } E m \times 1} 1^{\text {Cre }}$ (left panels) and Dag ${ }^{C K O} ; E m \times 1^{\text {Cre }}$ mice (right panels). Hoechst (magenta) labels the dentate gyrus and pyramidal cell body layer (SP) of CA1 and CA3. High magnification (20X) images of VGLUT3+ axon terminals (green) in the CA1 (B', B'), and CA3 (C', C") of Dag $1^{\text {Control }}$ :Emx $1^{\text {Cre }}$ and Dag $1^{\text {CKO }} ; E m \times 1^{\text {Cre }}$ mice. Single channel images of VGLUT3 signal (gray) are shown below (hippocampus) and to the right (CA1) of merged images. Dotted white boxes indicate locations of high magnification images. SO, stratum oriens; SP, stratum pyramidale; SR, stratum radiatum; SLM, stratum lacunosum-moleculare; SL, stratum lucidum. 

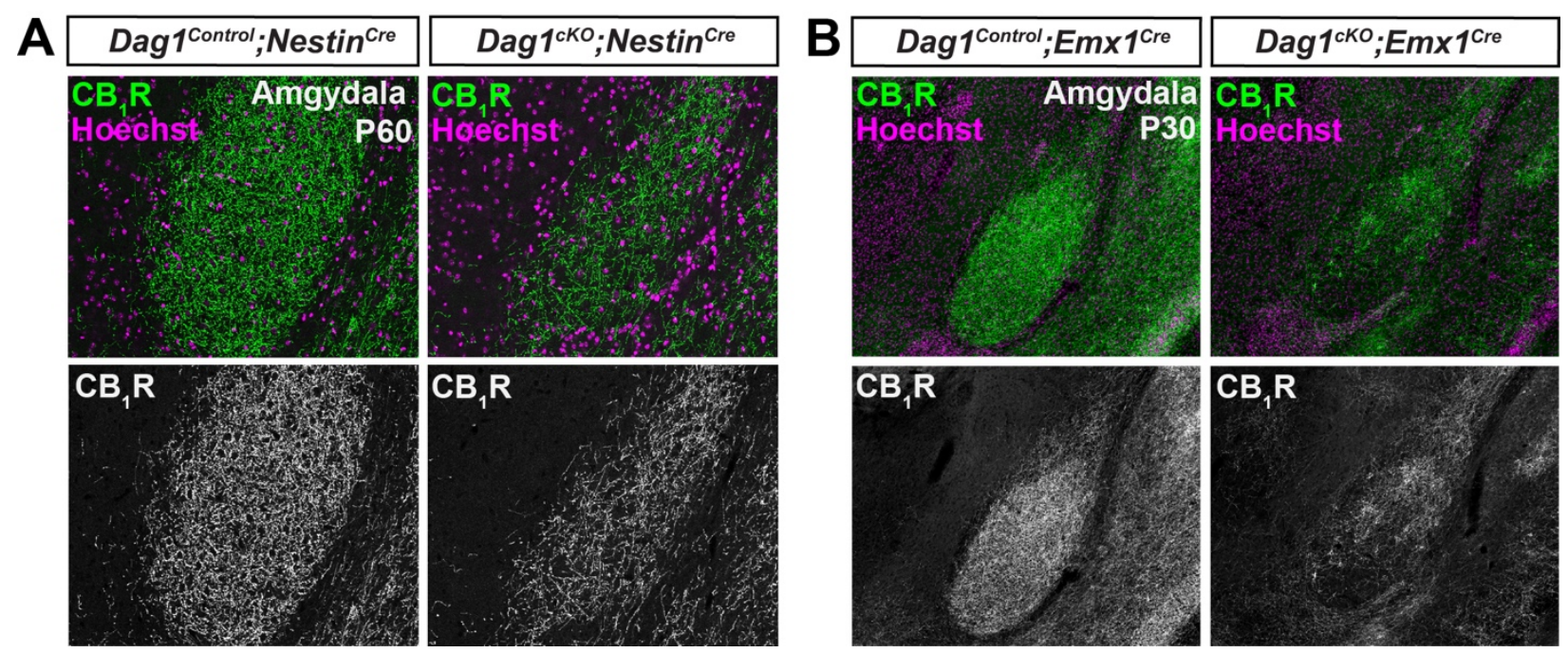

Figure S3. CCK+ interneuron innervation is impaired in the amygdala of Dag1 ${ }^{\text {cKo }}$ mice. (A, B) Immunostaining for $\mathrm{CB}_{1} \mathrm{R}$ (green) and Hoechst (magenta) shows abnormal $\mathrm{CCK}+$ innervation in the amygdala of (A) Dag $1^{\mathrm{cKO}} ; \mathrm{Nestin}{ }^{\mathrm{Cre}}$ and (B) Dag $1^{\mathrm{cKO}} ; \mathrm{Em} \times 1^{\mathrm{Cre}}$ mice (right panels). Single channel $\mathrm{CB}_{1} \mathrm{R}$ images (gray) are shown below. 

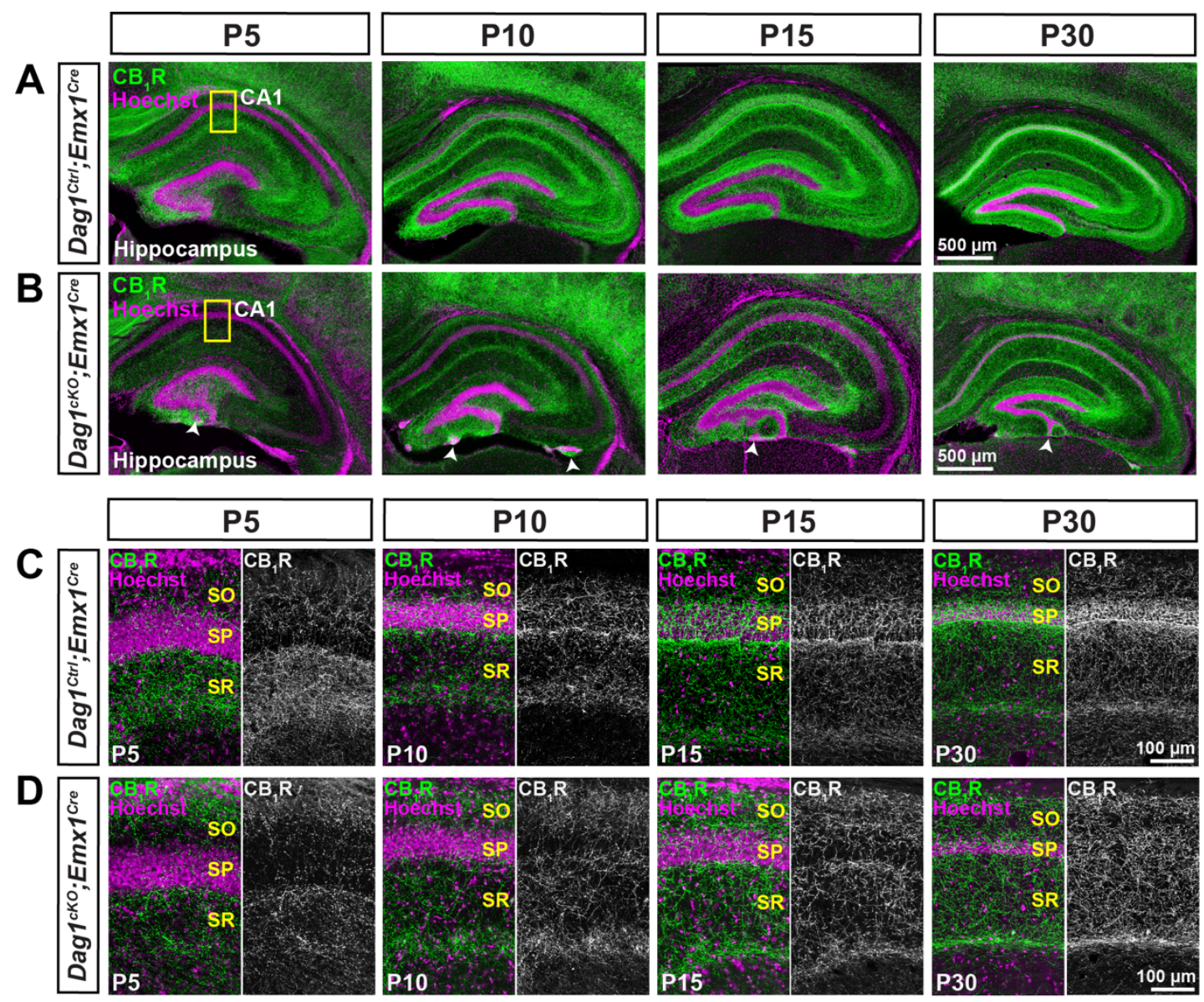

E
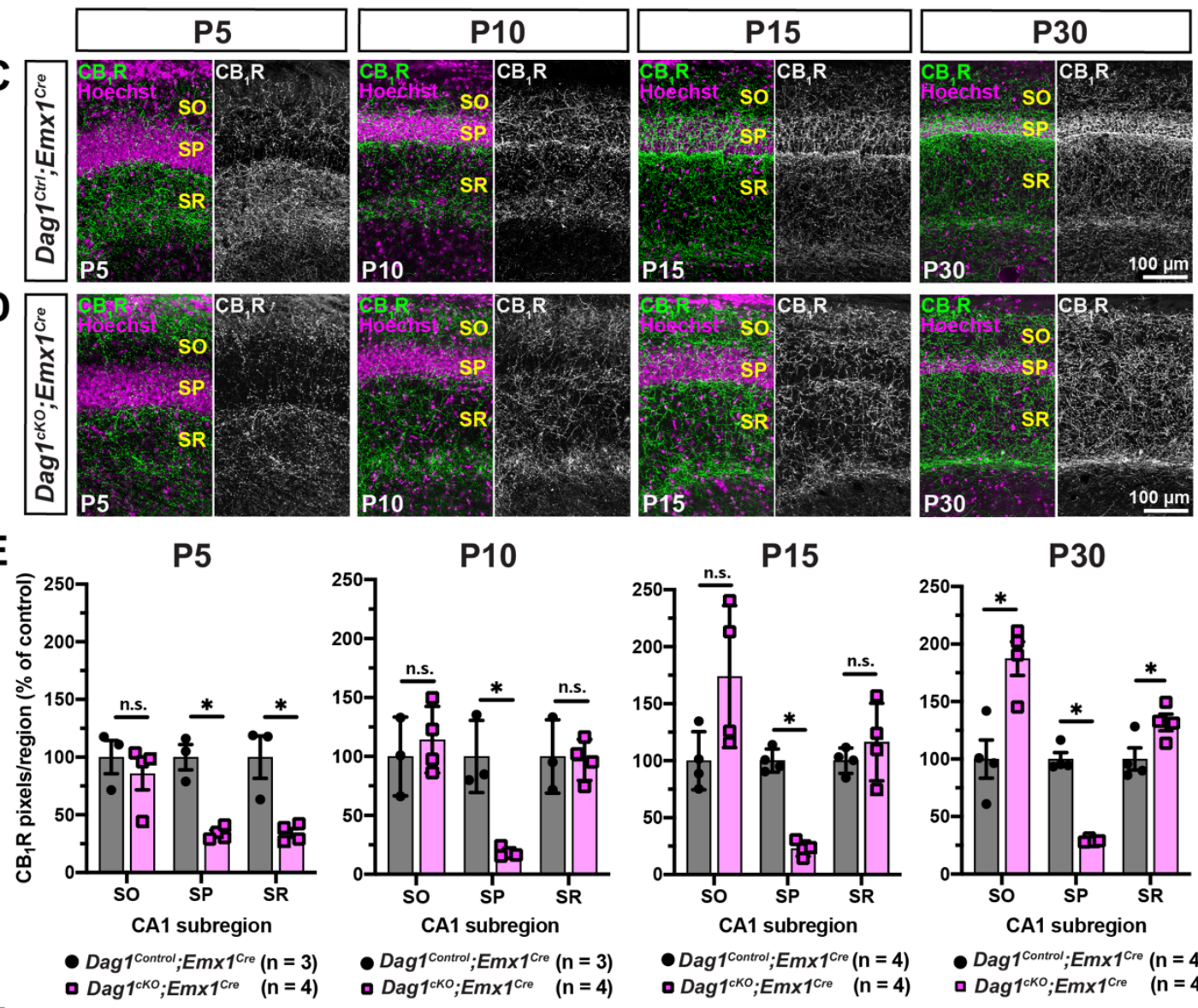

$\mathbf{F}$
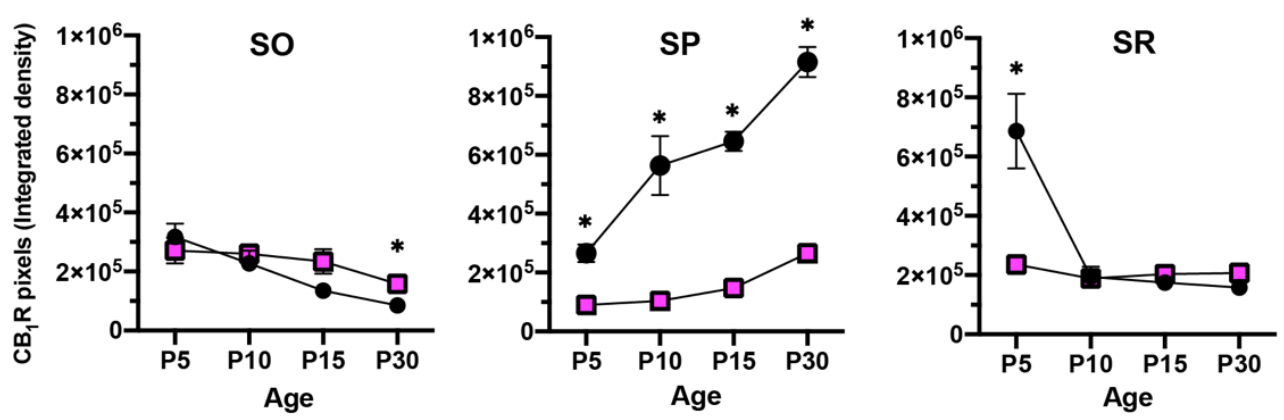

- Dag1
Control; $E m \times 1^{\text {cre }}$ 
Figure 3. Dystroglycan is required for CCK+ IN axon targeting during early postnatal development. (A-D) Immunostaining for $\mathrm{CB}_{1} \mathrm{R}+$ axon terminals (green) in the hippocampus (A, B) and CA1 (C, D) of Dag $1^{\text {Control; }}$ Em $x 1^{\text {Cre }}$ mice (top rows) and $D a g 1^{\mathrm{CKO}} ; E m \times 1^{\text {Cre }}$ mice (bottom rows) from postnatal day 5 to 30 (P5-30). White arrowheads indicate neuronal migration errors in Dag $1^{\mathrm{CKO}} ; E m \times 1^{\mathrm{Cre}}$ mice. Yellow boxes indicate approximate locations of high magnification images in C and D. (C-D) High magnification (20X) images of $\mathrm{CB}_{1} \mathrm{R}+$ axon terminals (green) in the CA1 of $D a 1^{C o n t r o l} ; E m \times 1^{C r e}(C)$, and Dag $1^{\text {CKO }} ; E m \times 1^{\text {Cre }}$ mice (D) from P5-P30. Hoechst (magenta) labels the pyramidal cell body layer (SP). Single channel images of $C_{B} R$ signal (gray) are shown to the right. (E) Quantification of $\mathrm{CB}_{1} \mathrm{R}$ pixels in hippocampal CA1 layers SO, SP, and SR of Dag $1^{\text {Control }} ; E m \times 1^{\text {Cre }}$ (gray) and Dag ${ }^{1 \mathrm{CKO}} ; E m \times 1^{\text {Cre }}$ (pink) mice $\left({ }^{*} P<0.05\right.$, unpaired two-tailed Student's t-test; $\mathrm{n}=3-4$ mice/genotype). Data points represent individual animals. Data are presented as mean values \pm s.e.m, and normalized to Dag $1^{\text {Control; }}$ Emx $1^{\text {Cre }}$ signal in each CA layer. (F) Quantification of non-

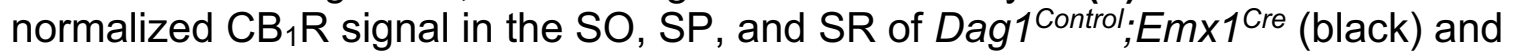
$D a g 1^{C K O} ; E m \times 1^{\text {Cre }}$ (pink) mice from P5-P30. $\left({ }^{*} P<0.05\right.$, unpaired two-tailed Student's ttest; $n=3-4$ mice/genotype). Data are presented as mean values \pm s.e.m. CA1 layers: $\mathrm{SO}$, stratum oriens; SP, stratum pyramidale; SR, stratum radiatum. 

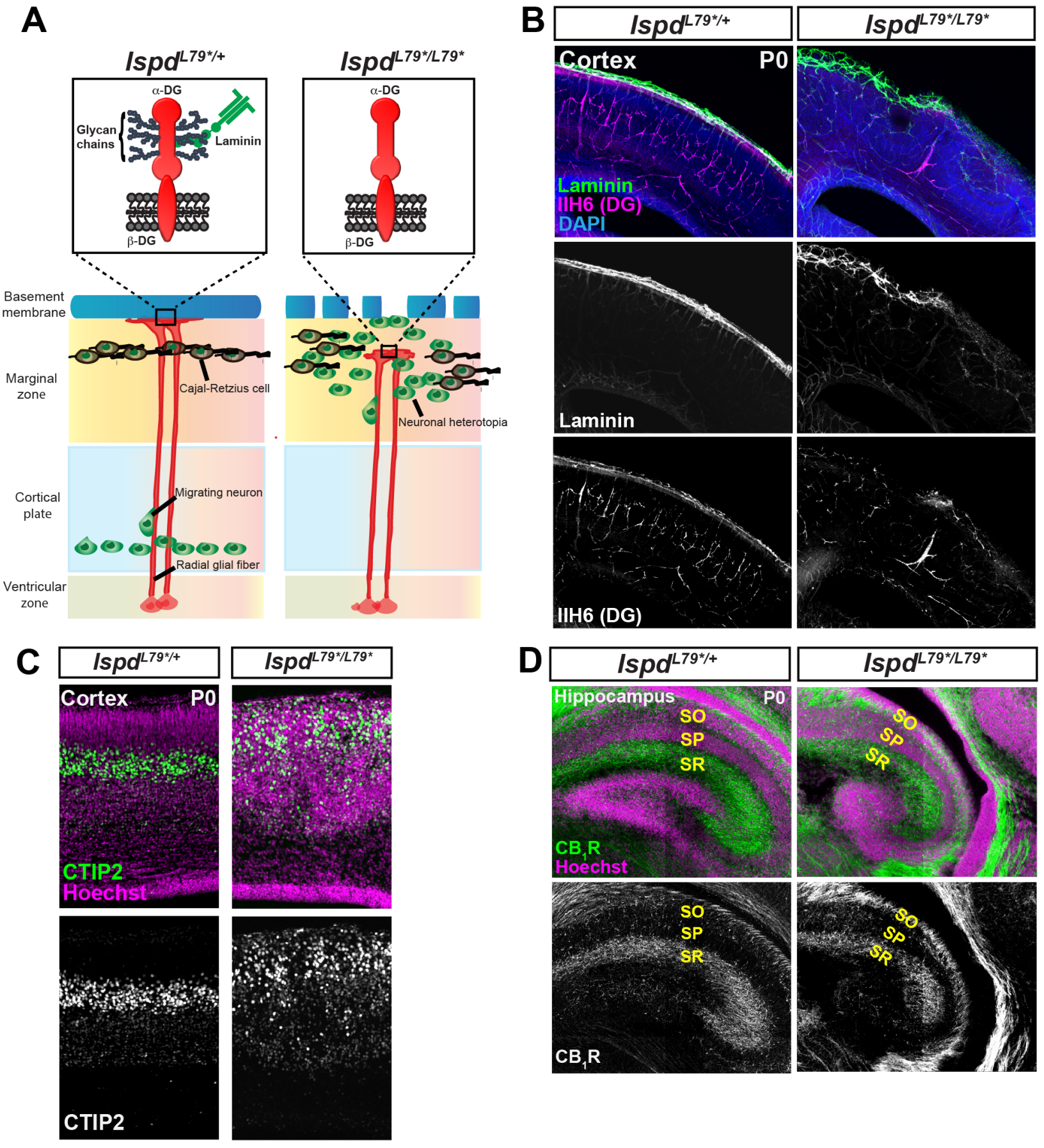

Figure 4. CCK+ interneuron terminals are present at birth in $I s p d^{L 79^{*}}$ mutant mice lacking Dystroglycan glycosylation. (A) Schematic showing lack of sugar chains on alpha Dystroglycan ( $\alpha$-DG) and impaired laminin binding due to a point mutation in Ispd (right). (B) Sections from P0 mice immunostained for the basement membrane marker laminin (green) and Dystroglycan (IIH6, magenta). In $/ s p d^{L 79^{*} /+}$ control mice (left), laminin and Dystroglycan co-localize at the cortical surface, whereas $I s p d^{L 79^{*} / L 9^{*}}$ mutant mice display loss of Dystroglycan staining and disruption of basement membrane architecture. (C) Sections immunostained for CTIP2 (L5, green) shows disrupted cortical 
layers and ectopic neurons in heterotopia of $I s p d^{L 79^{*} / L 79^{*}}$ mutant mice (right). (D) Hippocampal sections from PO $I s p d^{L 79^{* /+}}$ control (left) and $I s p d^{L 79^{*} / L 79^{*}}$ mutant mice (right) were immunostained for $\mathrm{CB}_{1} \mathrm{R}$ to label nascent $\mathrm{CB}_{1} \mathrm{R}+$ axon terminals. $\mathrm{CB}_{1} \mathrm{R}+$ axon terminals populate the $\mathrm{SR}$ of both control and mutant mice. Single channel images (gray) are shown below merged images. CA1 layers: SO, stratum oriens; SP, stratum pyramidale; SR, stratum radiatum. 
A

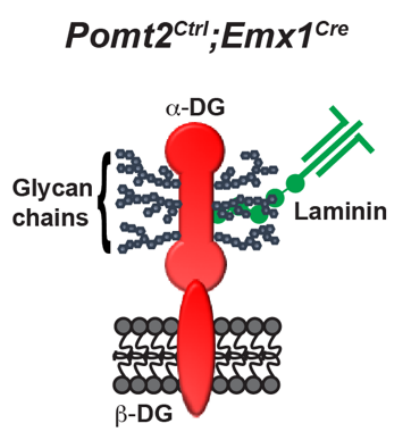

Pomt2 ${ }^{\text {cKo; }}$ Emx $1^{\text {cre }}$

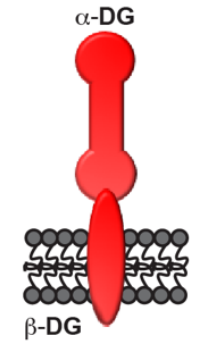

C
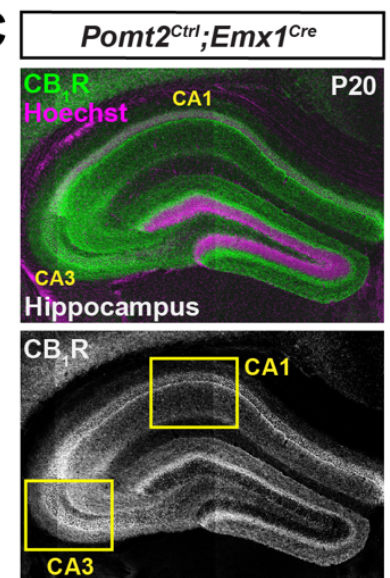

$\mathrm{CB}_{1} \mathrm{R}$
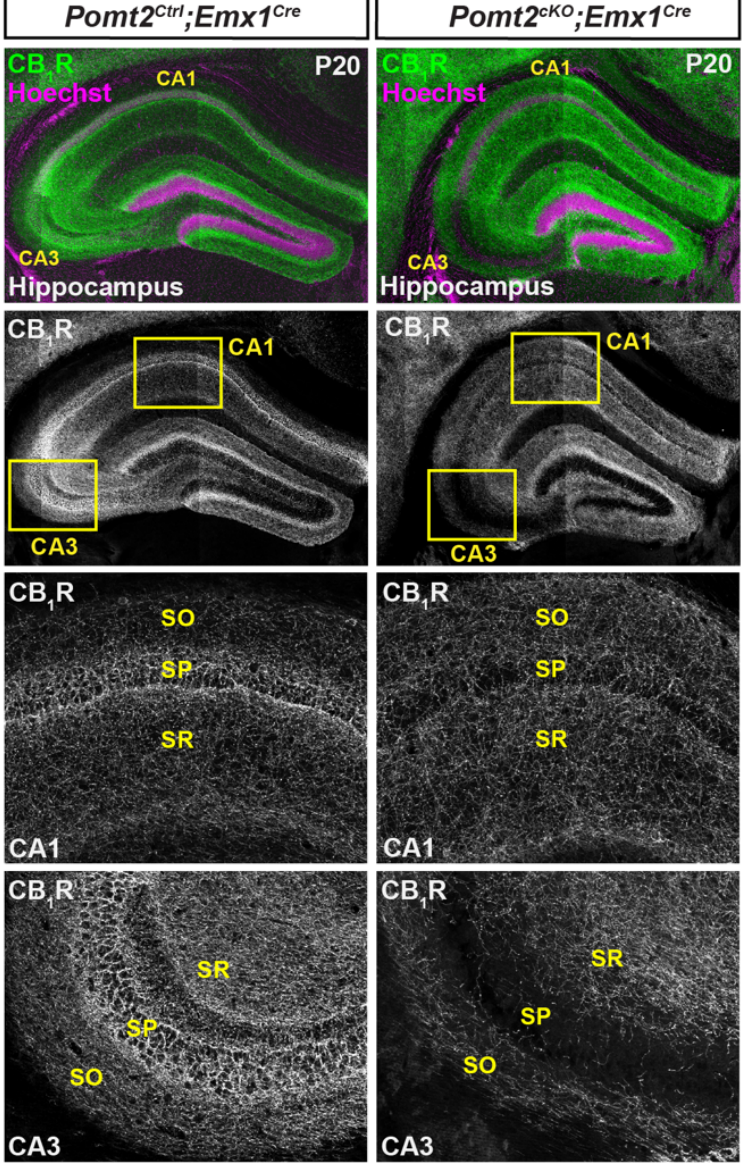

B
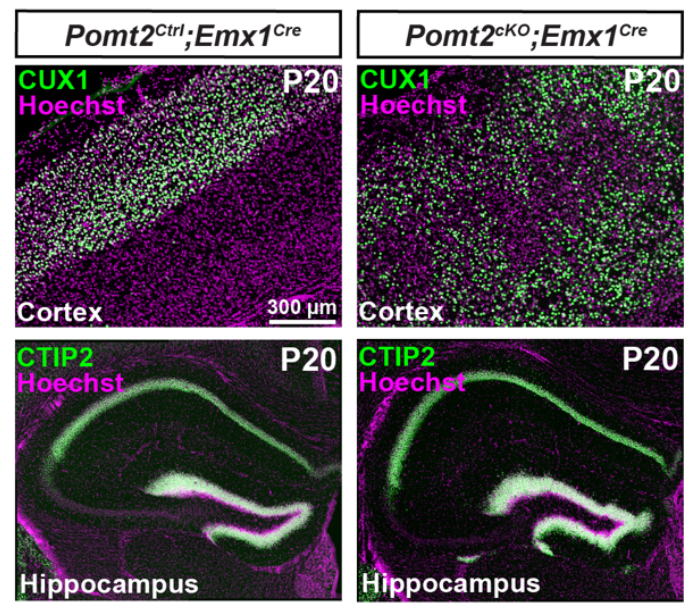

D
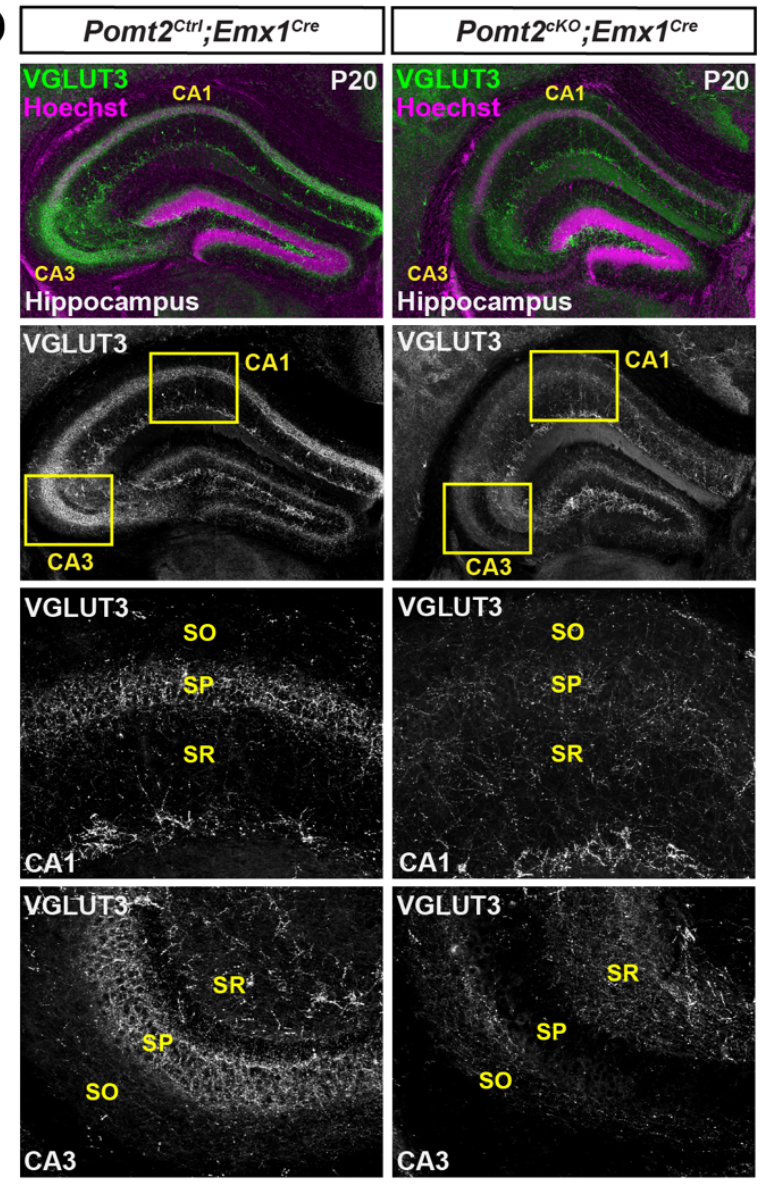

Figure 5. CCK+ interneuron axon targeting requires functional Dystroglycan glycosylation. (A) Schematic showing loss of sugar chains on alpha Dystroglycan $(\alpha-$ DG) due to conditional knockout of the glycosyltransferase gene Pomt2 (right). (B) Coronal sections immunostained for cortical layer marker CUX1 (L2-3, green, top panels) revealing abnormal neuronal migration in Pomt2 ${ }^{c K O} ; E m \times 1^{\mathrm{Cre}}$ mice (right panel). Hippocampal sections stained for CTIP2 (green, bottom panels) show ectopic neurons in the dentate gyrus of $\mathrm{Pomt}^{\mathrm{cKO}} ; \mathrm{Em} \times 1^{\mathrm{Cre}}$ mice (right panel). (C, D) Immunostaining for $\mathrm{CB}_{1} \mathrm{R}(\mathrm{C})$ and VGLUT3 (D) (green) shows abnormal distribution of CCK-IN axon 
terminals in the hippocampus of P20 Pomt $2^{c K O} ; E m \times 1^{\text {Cre }}$ mice (right panels). High magnification images (20X) of the CA1 and CA3 (yellow boxed regions) and single channel $\mathrm{CB}_{1} \mathrm{R}$ images (gray) are shown below. CA1 layers: SO, stratum oriens; $\mathrm{SP}$, stratum pyramidale; SR, stratum radiatum. 

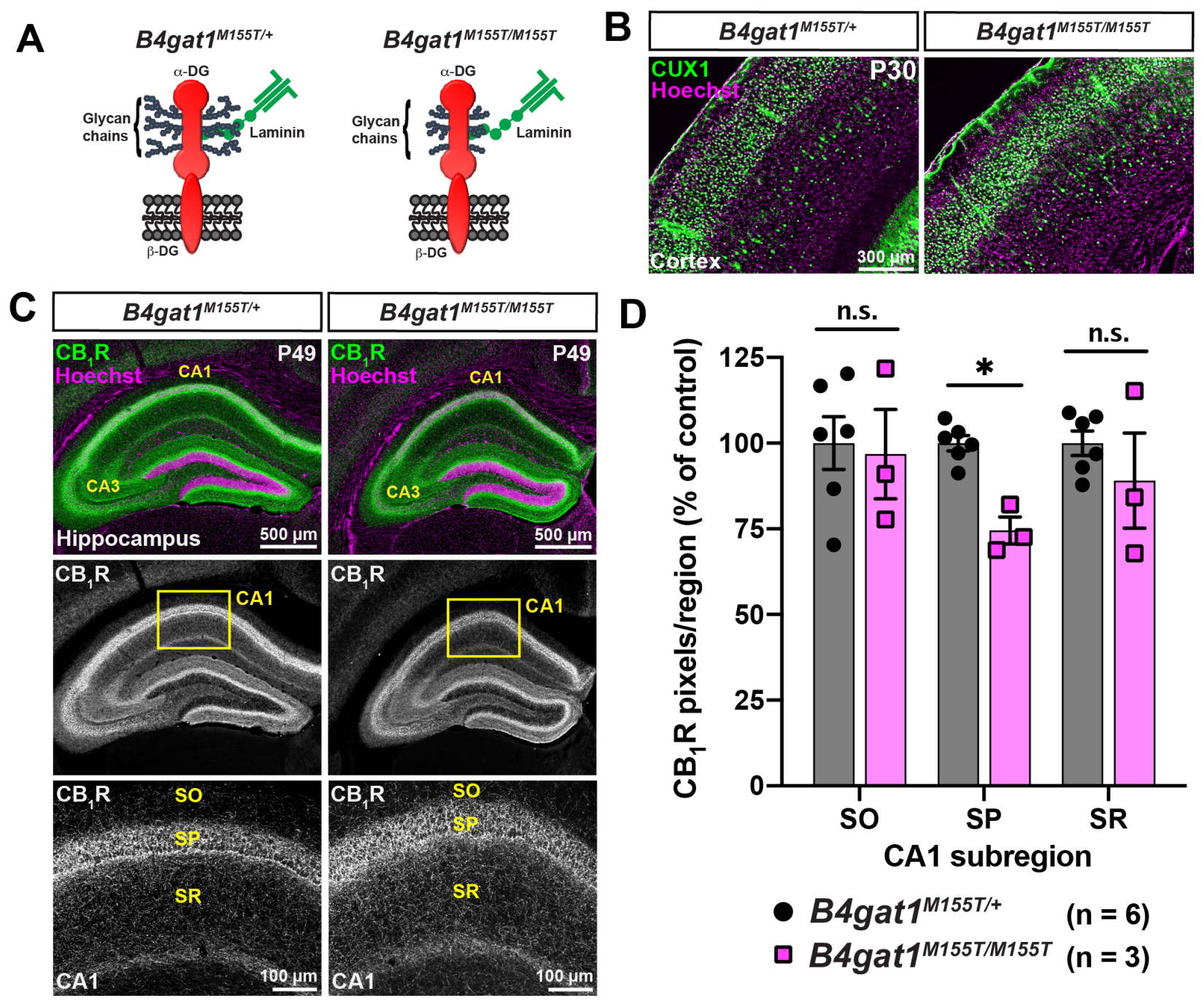

Figure 6. CCK+ interneuron axon targeting is only modestly affected in B4gat1 ${ }^{M 155 T}$ mutant mice with partial loss of Dystroglycan glycosylation. (A) Schematic showing fewer sugar chains on alpha Dystroglycan $(\alpha-D G)$ due to a point mutation in glycosyltransferase gene B4gat1 (right). (B) Sections immunostained for layer marker CUX1 (L2-3, green) shows normal migration of cortical neurons in B4gat1 ${ }^{\text {155T/M155T }}$ mutant mice (right). (C) Immunostaining for $\mathrm{CB}_{1} \mathrm{R}$ shows axon terminals (green) in the hippocampus of P49 B4gat $1^{\text {M155T/+ }}$ control (left panels) and B4gat ${ }^{\text {M155T/M155T }}$ mutant mice (right panels). High magnification images (20X) of the $\mathrm{CA} 1$ (yellow boxed regions) and single channel $\mathrm{CB}_{1} \mathrm{R}$ images (gray) are shown below. (D) Quantification of $\mathrm{CB}_{1} \mathrm{R}$ pixels in CA1 layers SO, SP, and SR from B4gat1 ${ }^{\mathrm{M} 155 \mathrm{~T} / \mathrm{+}}$ control (gray) and B4gat $1^{M 155 T / M 155 T}$ mutant mice (pink) $\left({ }^{*} P<0.05\right.$, unpaired two-tailed Student's t-test; n.s., not significant). Data are presented as mean values \pm s.e.m. Data are normalized to the signal measured in control mice for each CA layer. CA1 layers: $\mathrm{SO}$, stratum oriens; SP, stratum pyramidale; SR, stratum radiatum. 


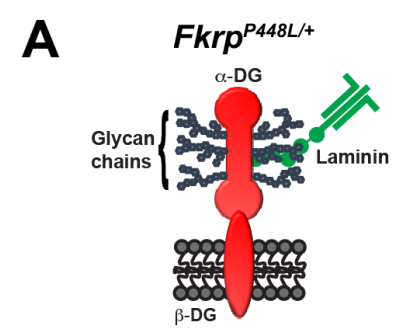

C
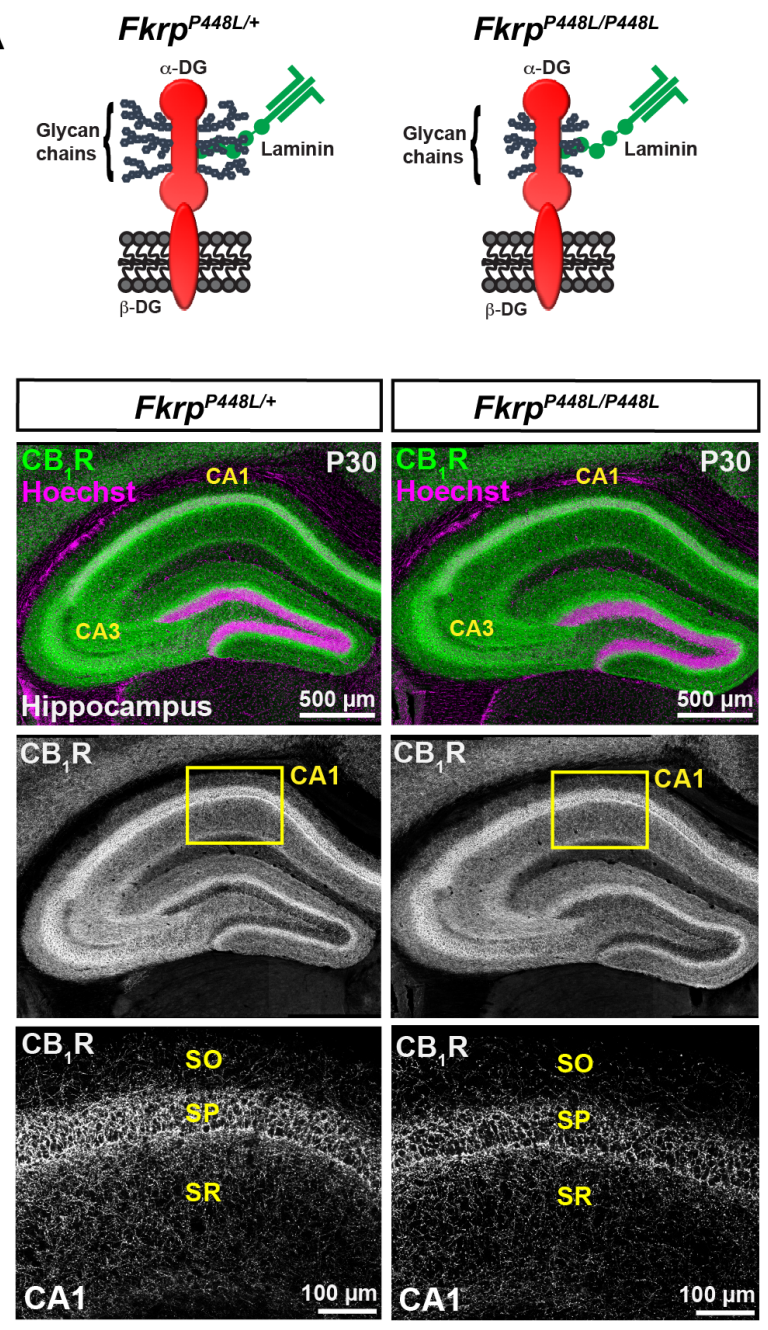

Fkrp $^{\text {P448L/P448L }}$
B
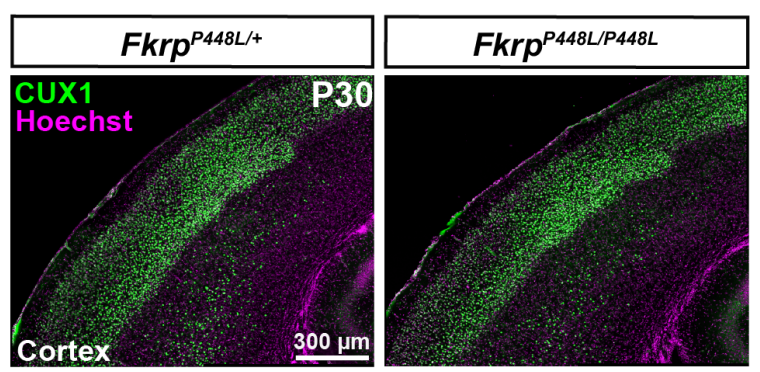

D

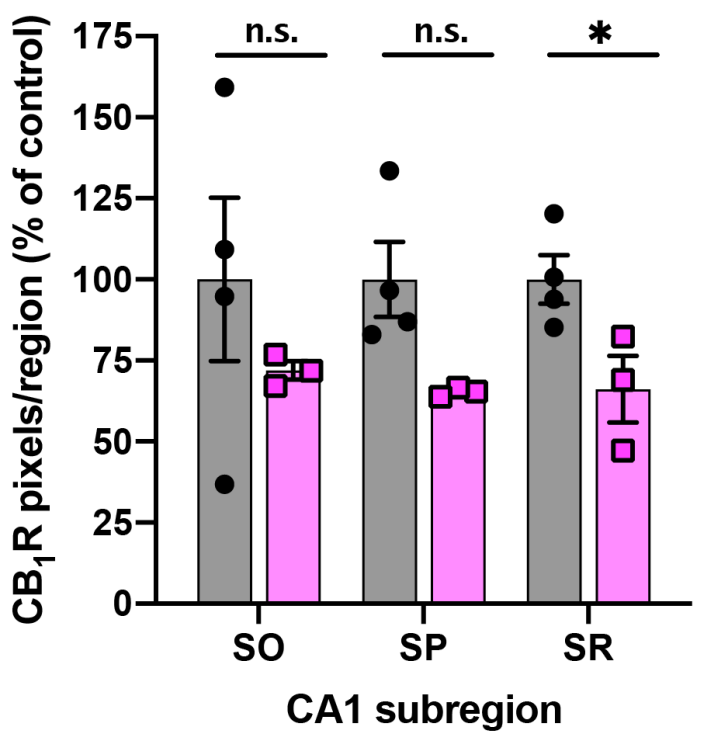

- $F k r p^{P 448 L /+} \quad(n=4)$

口 $\operatorname{Fkrp}^{\mathrm{P} 448 L P 448 L}(\mathrm{n}=3)$

Figure 7. CCK+ interneuron axon targeting is only modestly affected in Fkrp $^{\text {P448L }}$ mutant mice with partial loss of Dystroglycan glycosylation. (A) Schematic showing fewer sugar chains on alpha Dystroglycan ( $\alpha-D G)$ due to a point mutation in the gene Fkrp (right). (B) Sections immunostained for layer marker CUX1 (L2-3, green) shows normal migration of cortical neurons in Fkrp ${ }^{P 448 L / P 448 L}$ mutant mice (right). (C) Immunostaining for $\mathrm{CB}_{1} \mathrm{R}$ shows axon terminals (green) in the hippocampus of

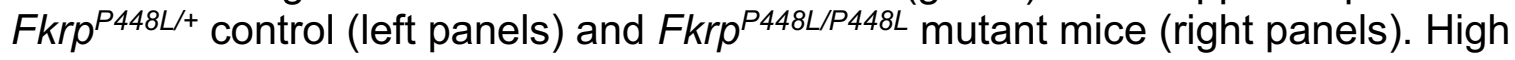
magnification images (20X) of the CA1 (yellow boxed regions) and single channel $C_{1} R$ images (gray) are shown below. (D) Quantification of $\mathrm{CB}_{1} \mathrm{R}$ pixels in $\mathrm{CA} 1$ layers $\mathrm{SO}$, $\mathrm{SP}$, and SR from Fkrp ${ }^{P 448 L /+}$ control (gray) and $F k r p^{P 448 L / P 448 L}$ mutant mice (pink) ( ${ }^{*} P<$ 0.05 , unpaired two-tailed Student's t-test; n.s., not significant). Data are presented as mean values \pm s.e.m. Data are normalized to the signal measured in control mice for each CA layer. CA1 layers: SO, stratum oriens; SP, stratum pyramidale; SR, stratum radiatum. 

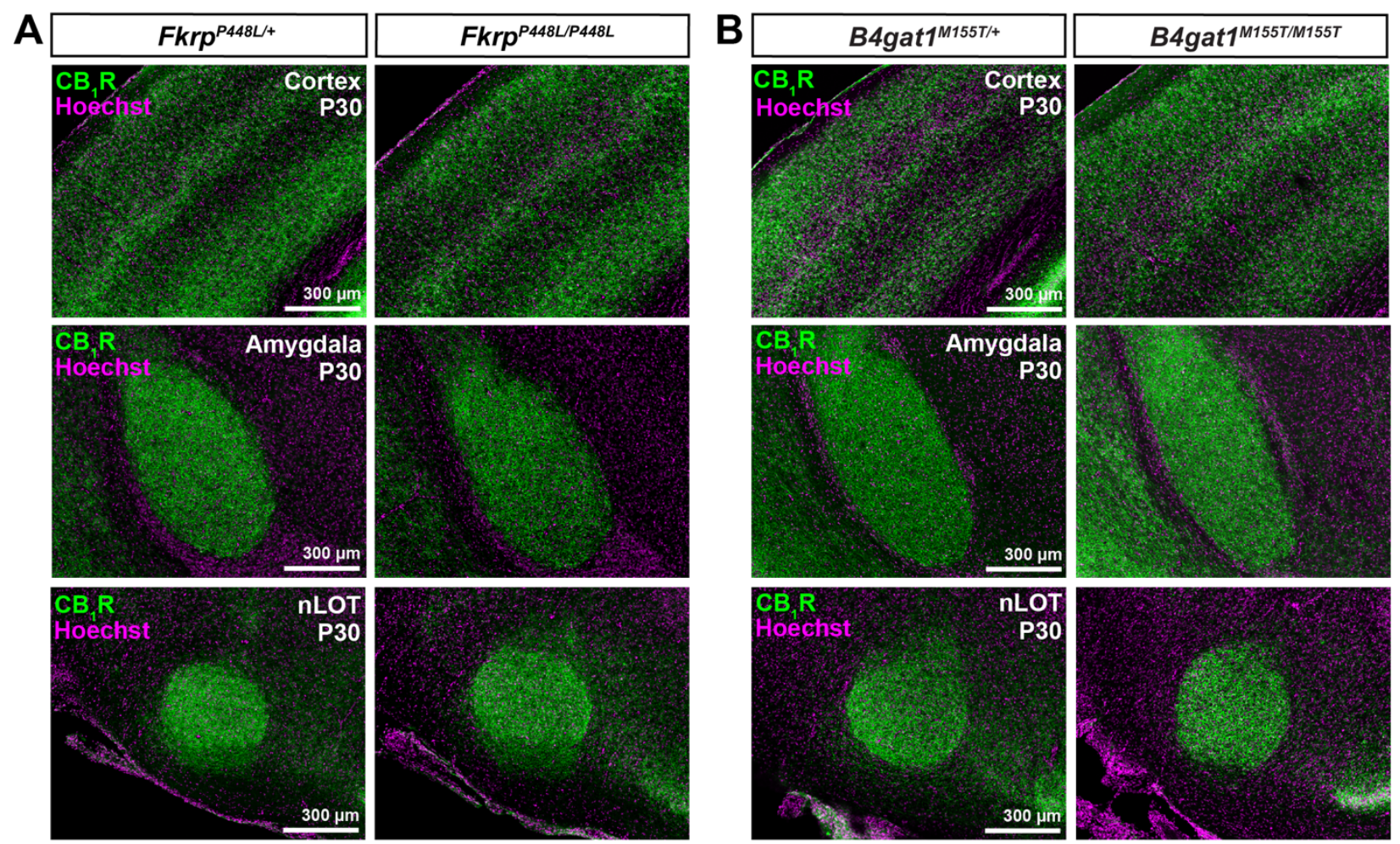

Figure S4. CCK+ interneuron innervation in the cortex and amygdala is normal in models of mild dystroglycanopathy. (A) Immunostaining for $\mathrm{CB}_{1} \mathrm{R}+$ axon terminals (green) in the cortex (top), amygdala (middle) and nucleus of the lateral olfactory tract (nLOT, bottom) of P30 Fkrp ${ }^{P 448 L /+}$ control (left panels) and $\mathrm{Fkrp}^{\mathrm{P448L} / \mathrm{P} 448 \mathrm{~L}}$ mutant mice (right panels). (B) Immunostaining for $\mathrm{CB}_{1} \mathrm{R}+$ axon terminals (green) in the cortex (top), amygdala (middle) and nucleus of the lateral olfactory tract (nLOT, bottom) of P30 $B 4$ gat $1^{M 155 T /+}$ control (left panels) and B4gat1 ${ }^{M 155 T / M 155 T}$ mutant mice (right panels). 
A

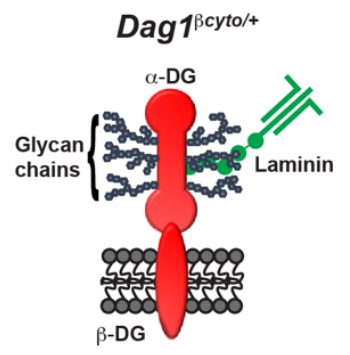

$\mathbf{C}$
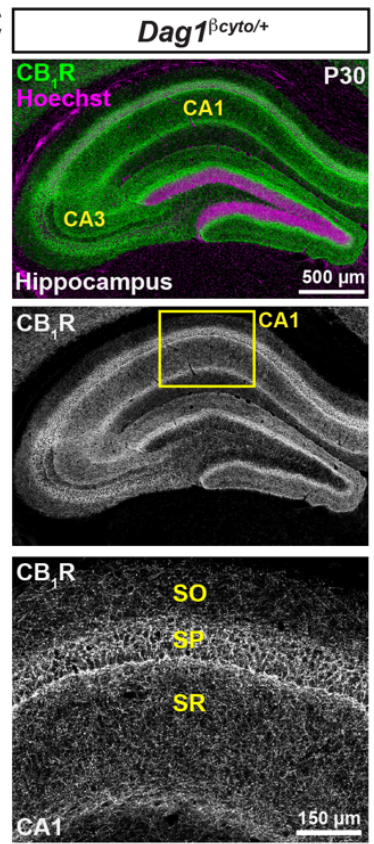
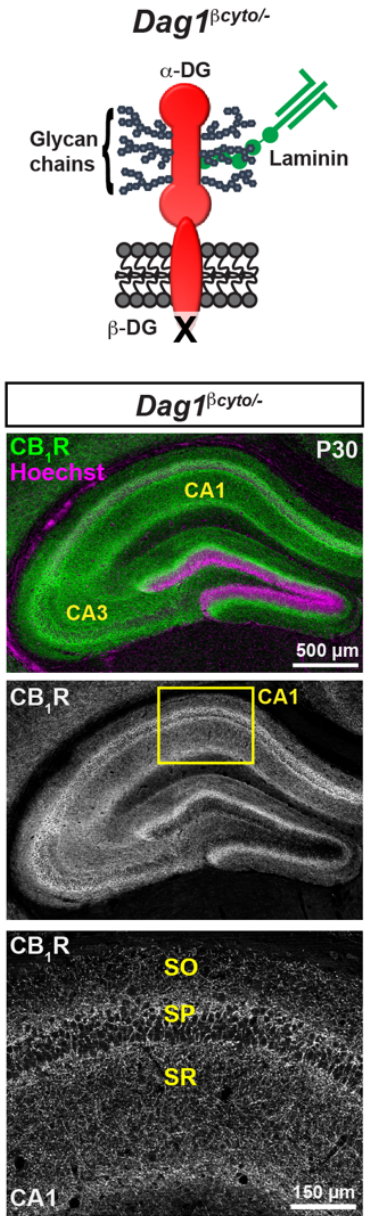

B
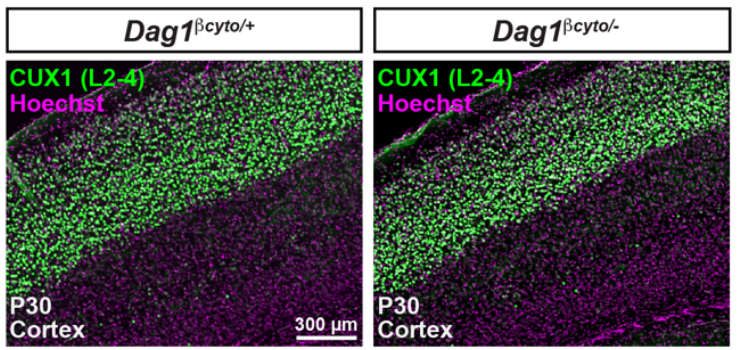

D

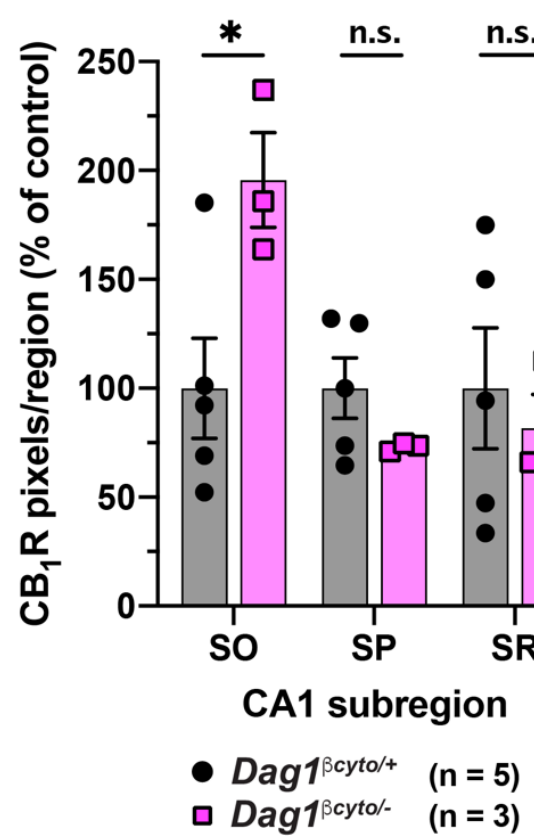

Figure 8. Deletion of the cytoplasmic domain of $\beta$-Dystroglycan leads to minor alterations in CCK+ interneuron axon targeting. (A) Schematic showing transmembrane $\beta$-Dystroglycan subunit. Dag ${ }^{\text {ccyto/- }}$ mutant mice (right) lack the intracellular domain of $\beta$-Dystroglycan. (B) Sections immunostained for layer marker CUX1 (L2-3, green) shows normal migration of cortical neurons in P30 Dag1/cyto/mutant mice. (C) Sections from Dag $1^{\text {cyto/+ }}$ control (left panels) and Dag $1^{\text {cyto/- }}$ mutant mice (right panels) immunostained for $\mathrm{CB}_{1} \mathrm{R}+$ axon terminals (green). Single channel images of $\mathrm{CB}_{1} \mathrm{R}$ (gray) in the hippocampus and $\mathrm{CA} 1$ are shown below the merged images. Yellow boxes indicate approximate locations of CA1 high magnification (20X) images (bottom panels). (D) Quantification of $\mathrm{CB}_{1} \mathrm{R}$ pixels in CA1 layers SO, SP, and

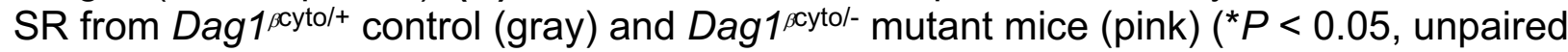
two-tailed Student's t-test; n.s., not significant). Data are presented as mean values \pm s.e.m. Data are normalized to the signal measured in control mice for each CA layer. CA1 layers: SO, stratum oriens; SP, stratum pyramidale; SR, stratum radiatum. 

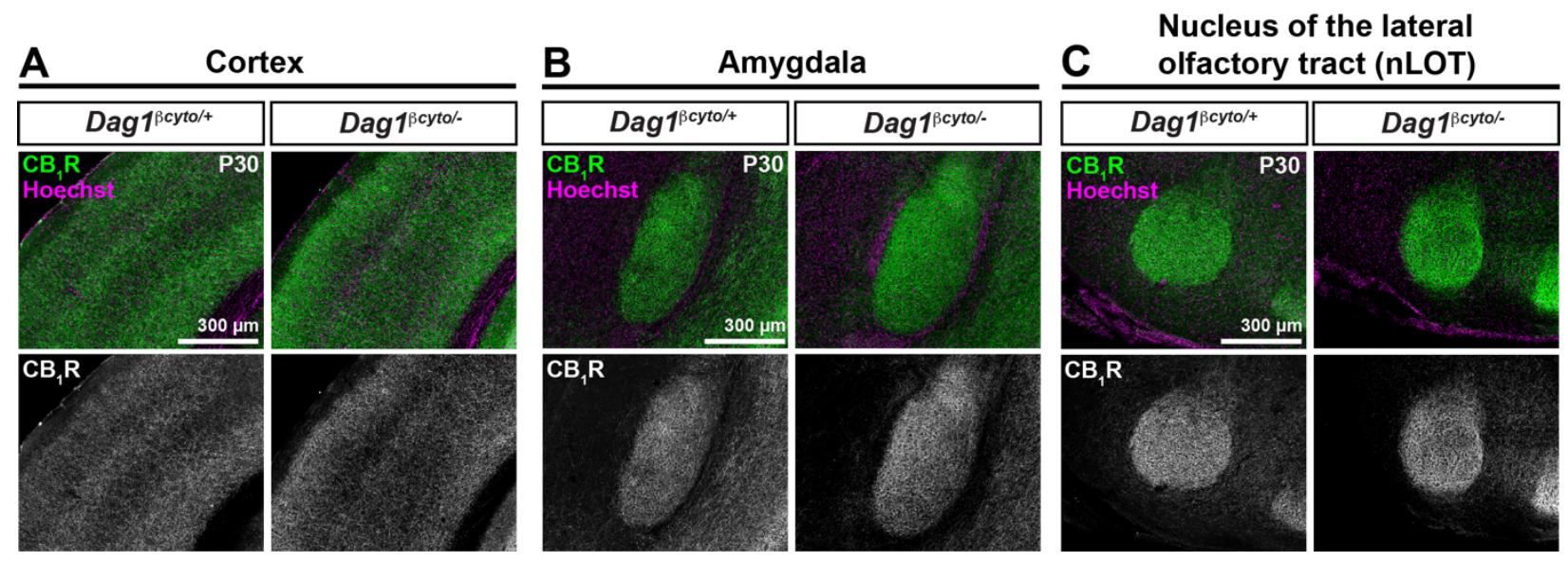

Figure S5. CCK+ interneuron innervation appears normal in multiple forebrain regions of $\beta$-Dystroglycan mutant mice. (A-C) Immunostaining for $\mathrm{CB}_{1} \mathrm{R}+$ axon terminals (green) and Hoechst (magenta) in the cortex (A), amygdala (B), and nucleus of the lateral olfactory tract (C) of P30 Dag $1^{\text {cyto/+ }}$ control (left panels) and Dag $1^{1 \text { cyto/- }}$ mutant mice (right panels). Single channel images of $\mathrm{CB}_{1} \mathrm{R}$ (gray) are shown below. 


\section{REFERENCES}

Awano, H., Blaeser, A., Keramaris, E., Xu, L., Tucker, J., Wu, B., Lu, P., and Lu, Q.L. (2015). Restoration of Functional Glycosylation of $\alpha$-Dystroglycan in FKRP Mutant Mice Is Associated with Muscle Regeneration. Am. J. Pathol. 185, 20252037.

Barresi, R., and Campbell, K.P. (2006). Dystroglycan: from biosynthesis to pathogenesis of human disease. J Cell Sci 119, 199-207.

Berghuis, P., Rajnicek, A.M., Morozov, Y.M., Ross, R.A., Mulder, J., Urbán, G.M., Monory, K., Marsicano, G., Matteoli, M., Canty, A., et al. (2007). Hardwiring the brain: endocannabinoids shape neuronal connectivity. Science 316, 1212-1216.

Blaeser, A., Keramaris, E., Chan, Y.M., Sparks, S., Cowley, D., Xiao, X., and Lu, Q.L. (2013). Mouse models of fukutin-related protein mutations show a wide range of disease phenotypes. Hum. Genet. 132, 923-934.

Bouchet-Séraphin, C., Vuillaumier-Barrot, S., and Seta, N. (2015). Dystroglycanopathies: About Numerous Genes Involved in Glycosylation of One Single Glycoprotein. J Neuromuscul Dis 2, 27-38.

Briatore, F., Patrizi, A., Viltono, L., Sassoè-Pognetto, M., and Wulff, P. (2010). Quantitative organization of GABAergic synapses in the molecular layer of the mouse cerebellar cortex. PLoS One 5, e12119.

Briatore, F., Pregno, G., Di Angelantonio, S., Frola, E., De Stefano, M.E., Vaillend, C., Sassoè-Pognetto, M., and Patrizi, A. (2020). Dystroglycan mediates clustering of essential GABAergic components in cerebellar Purkinje cells. Front. Mol. Neurosci. 13.

Brockington, M., Blake, D.J., Prandini, P., Brown, S.C., Torelli, S., Benson, M.A., Ponting, C.P., Estournet, B., Romero, N.B., Mercuri, E., et al. (2001). Mutations in the fukutin-related protein gene (FKRP) cause a form of congenital muscular dystrophy with secondary laminin alpha2 deficiency and abnormal glycosylation of alpha-Dystroglycan. Am. J. Hum. Genet. 69, 1198-1209.

Brunig, I., Suter, A., Knuesel, I., Luscher, B., and Fritschy, J.M. (2002). GABAergic terminals are required for postsynaptic clustering of dystrophin but not of $\operatorname{GABA}(\mathrm{A})$ receptors and gephyrin. The Journal of Neuroscience 22, 4805-4813.

Busquets-Garcia, A., Oliveira da Cruz, J.F., Terral, G., Pagano Zottola, A.C., SoriaGómez, E., Contini, A., Martin, H., Redon, B., Varilh, M., Ioannidou, C., et al. (2018). Hippocampal CB1 receptors control incidental associations. Neuron 99, 1247-1259.e7. 
Buysse, K., Riemersma, M., Powell, G., van Reeuwijk, J., Chitayat, D., Roscioli, T., Kamsteeg, E.-J., van den Elzen, C., van Beusekom, E., Blaser, S., et al. (2013). Missense mutations in $\beta-1,3-N$-acetylglucosaminyltransferase 1 (B3GNT1) cause Walker-Warburg syndrome. Hum. Mol. Genet. 22, 1746-1754.

Calvigioni, D., Mate, Z., Fuzik, J., Girach, F., Zhang, M.D., Varro, A., Beiersdorf, J., Schwindling, C., Yanagawa, Y., Dockray, G.J., et al. (2017). Functional Differentiation of Cholecystokinin-Containing Interneurons Destined for the Cerebral Cortex. Cereb Cortex 4, 2453-2468.

Campanelli, J.T., Roberds, S.L., Campbell, K.P., and Scheller, R.H. (1994). A role for dystrophin-associated glycoproteins and utrophin in agrin-induced AChR clustering. Cell 77, 663-674.

Cataldi, M.P., Lu, P., Blaeser, A., and Lu, Q.L. (2018). Ribitol restores functionally glycosylated $\alpha$-dystroglycan and improves muscle function in dystrophic FKRPmutant mice. Nat. Commun. 9, 3448.

Cataldi, M.P., Blaeser, A., Lu, P., Leroy, V., and Lu, Q.L. (2020). ISPD Overexpression Enhances Ribitol-Induced Glycosylation of a-Dystroglycan in Dystrophic FKRP Mutant Mice. Mol Ther Methods Clin Dev 17, 271-280.

Chanda, S., Hale, W.D., Zhang, B., Wernig, M., and Südhof, T.C. (2017). Unique versus redundant functions of neuroligin genes in shaping excitatory and inhibitory synapse properties. J. Neurosci. 37, 6816-6836.

Chen, L.Y., Jiang, M., Zhang, B., Gokce, O., and Sudhof, T.C. (2017). Conditional Deletion of All Neurexins Defines Diversity of Essential Synaptic Organizer Functions for Neurexins. Neuron 94, 611-625 e614.

Clement, E., Mercuri, E., Godfrey, C., Smith, J., Robb, S., Kinali, M., Straub, V., Bushby, K., Manzur, A., Talim, B., et al. (2008). Brain involvement in muscular dystrophies with defective Dystroglycan glycosylation. Ann. Neurol. 64, 573-582.

Clements, R., Turk, R., Campbell, K.P., and Wright, K.M. (2017). Dystroglycan Maintains Inner Limiting Membrane Integrity to Coordinate Retinal Development. The Journal of Neuroscience 37, 8559-8574.

Clements, R., and Wright, K.M. (2018). Retinal ganglion cell axon sorting at the optic chiasm requires Dystroglycan. Dev. Biol. 442, 210-219.

Cohn, R.D., Henry, M.D., Michele, D.E., Barresi, R., Saito, F., Moore, S.A., Flanagan, J.D., Skwarchuk, M.W., Robbins, M.E., Mendell, J.R., et al. (2002). Disruption of DAG1 in differentiated skeletal muscle reveals a role for Dystroglycan in muscle regeneration. Cell 110, 639-648. 
Colognato, H., Galvin, J., Wang, Z., Relucio, J., Nguyen, T., Harrison, D., Yurchenco, P.D., and Ffrench-Constant, C. (2007). Identification of dystroglycan as a second laminin receptor in oligodendrocytes, with a role in myelination.

Development 134, 1723-1736.

Dalva, M.B., McClelland, A.C., and Kayser, M.S. (2007). Cell adhesion molecules: signalling functions at the synapse. Nat. Rev. Neurosci. 8, 206-220.

Del Pino, I., Brotons-Mas, J.R., Marques-Smith, A., Marighetto, A., Frick, A., Marin, O., and Rico, B. (2017). Abnormal wiring of CCK(+) basket cells disrupts spatial information coding. Nat Neurosci 20, 784-792.

Dempsey, C.E., Bigotti, M.G., Adams, J.C., and Brancaccio, A. (2019). Analysis of aDystroglycan/LG domain binding modes: Investigating protein motifs that regulate the affinity of isolated LG domains. Front. Mol. Biosci. 6, 18.

Eggan, S.M., and Lewis, D.A. (2007). Immunocytochemical distribution of the cannabinoid $\mathrm{CB} 1$ receptor in the primate neocortex: a regional and laminar analysis. Cereb. Cortex 17, 175-191.

Eggan, S.M., Melchitzky, D.S., Sesack, S.R., Fish, K.N., and Lewis, D.A. (2010a). Relationship of cannabinoid CB1 receptor and cholecystokinin immunoreactivity in monkey dorsolateral prefrontal cortex. Neuroscience 169, 1651-1661.

Eggan, S.M., Mizoguchi, Y., Stoyak, S. R., \& Lewis, D. A. (2010b). Development of cannabinoid 1 receptor protein and messenger RNA in monkey dorsolateral prefrontal cortex. Cerebral cortex 20(5), 1164-1174.

Ervasti, J.M., and Campbell, K.P. (1991). Membrane organization of the dystrophinglycoprotein complex. Cell 66, 1121-1131.

Fruh, S., Romanos, J., Panzanelli, P., Burgisser, D., Tyagarajan, S.K., Campbell, K.P., Santello, M., and Fritschy, J.M. (2016). Neuronal Dystroglycan Is Necessary for Formation and Maintenance of Functional CCK-Positive Basket Cell Terminals on Pyramidal Cells. J Neurosci 36, 10296-10313.

Gee, S.H., Montanaro, F., Lindenbaum, M.H., and Carbonetto, S. (1994). Dystroglycanalpha, a dystrophin-associated glycoprotein, is a functional agrin receptor. Cell $77,675-686$.

Giagtzoglou, N., Ly, C.V., and Bellen, H.J. (2009). Cell adhesion, the backbone of the synapse: "vertebrate" and "invertebrate" perspectives. Cold Spring Harb. Perspect. Biol. 1, a003079. 
Glass, M., Dragunow, M., and Faull, R.L. (1997). Cannabinoid receptors in the human brain: a detailed anatomical and quantitative autoradiographic study in the fetal, neonatal and adult human brain. Neuroscience 77, 299-318.

Godfrey, C., Clement, E., Mein, R., Brockington, M., Smith, J., Talim, B., Straub, V., Robb, S., Quinlivan, R., Feng, L., et al. (2007). Refining genotype phenotype correlations in muscular dystrophies with defective glycosylation of Dystroglycan. Brain 130, 2725-2735.

Gorski, J.A., Talley, T., Qiu, M., Puelles, L., Rubenstein, J.L.R., and Jones, K.R. (2002). Cortical excitatory neurons and Glia, but not GABAergic neurons, are produced in the Emx1-expressing lineage. J. Neurosci. 22, 6309-6314.

Graus-Porta, D., Blaess, S., Senften, M., Littlewood-Evans, A., Damsky, C., Huang, Z., Orban, P., Klein, R., Schittny, J.C., and Müller, U. (2001). Beta1-class integrins regulate the development of laminae and folia in the cerebral and cerebellar cortex. Neuron 31, 367-379.

Gumlaw, N., Sevigny, L.M., Zhao, H., Luo, Z., Bangari, D.S., Masterjohn, E., Chen, Y., McDonald, B., Magnay, M., Travaline, T., et al. (2020). biAb Mediated Restoration of the Linkage between Dystroglycan and Laminin-211 as a Therapeutic Approach for a-Dystroglycanopathies. Mol. Ther. 28, 664-676.

Guo, H., Hong, S., Jin, X.L., Chen, R.S., Avasthi, P.P., Tu, Y.T., Ivanco, T.L., and Li, Y. (2000). Specificity and efficiency of Cre-mediated recombination in Emx1-Cre knock-in mice. Biochem. Biophys. Res. Commun. 273, 661-665.

Holt, K.H., Crosbie, R.H., Venzke, D.P., and Campbell, K.P. (2000). Biosynthesis of Dystroglycan: processing of a precursor propeptide. FEBS Lett. 468, 79-83.

Hu, H., Liu, Y., Bampoe, K., He, Y., and Yu, M. (2016). Postnatal gene therapy improves spatial learning despite the presence of neuronal ectopia in a model of neuronal migration disorder. Genes (Basel) 7, 105.

Ibraghimov-Beskrovnaya, O., Ervasti, J.M., Leveille, C.J., Slaughter, C.A., Sernett, S.W., and Campbell, K.P. (1992). Primary structure of dystrophin-associated glycoproteins linking dystrophin to the extracellular matrix. Nature 355, 696-702.

Jagadha, V., and Becker, L.E. (1988). Brain morphology in Duchenne muscular dystrophy: A Golgi study. Pediatr. Neurol. 4, 87-92.

Jensen, K.R., Berthoux, C., Nasrallah, K., and Castillo, P.E. (2021). Multiple cannabinoid signaling cascades powerfully suppress recurrent excitation in the hippocampus. Proc. Natl. Acad. Sci. U. S. A. 118, e2017590118. 
Kanagawa, M., Nishimoto, A., Chiyonobu, T., Takeda, S., Miyagoe-Suzuki, Y., Wang, F., Fujikake, N., Taniguchi, M., Lu, Z., Tachikawa, M., et al. (2009). Residual laminin-binding activity and enhanced dystroglycan glycosylation by LARGE in novel model mice to dystroglycanopathy. Hum. Mol. Genet. 18, 621-631.

Knuesel, I., Mastrocola, M., Zuellig, R.A., Bornhauser, B., Schaub, M.C., and Fritschy, J.M. (1999). Short communication: altered synaptic clustering of GABAA receptors in mice lacking dystrophin (mdx mice). Eur. J. Neurosci. 11, 44574462.

Krasowska, E., Zabłocki, K., Górecki, D.C., and Swinny, J.D. (2014). Aberrant location of inhibitory synaptic marker proteins in the hippocampus of dystrophin-deficient mice: implications for cognitive impairment in duchenne muscular dystrophy. PLoS One 9, e108364.

Krueger-Burg, D., Papadopoulos, T., and Brose, N. (2017). Organizers of inhibitory synapses come of age. Current Opinion in Neurobiology 45, 66-77.

Levi, S., Grady, R.M., Henry, M.D., Campbell, K.P., Sanes, J.R., and Craig, A.M. (2002). Dystroglycan is selectively associated with inhibitory GABAergic synapses but is dispensable for their differentiation. J Neurosci 22, 4274-4285.

Liang, H., Hippenmeyer, S., and Ghashghaei, H.T. (2012). A Nestin-cre transgenic mouse is insufficient for recombination in early embryonic neural progenitors. Biol. Open 1, 1200-1203.

Lindenmaier, L.B., Parmentier, N., Guo, C., Tissir, F., and Wright, K.M. (2019). Dystroglycan is a scaffold for extracellular axon guidance decisions. Elife 8.

Liu, X., Somel, M., Tang, L., Yan, Z., Jiang, X., Guo, S., Yuan, Y., He, L., Oleksiak, A., Zhang, Y., et al. (2012). Extension of cortical synaptic development distinguishes humans from chimpanzees and macaques. Genome Res. 22, 611-622.

Manya, H., Chiba, A., Yoshida, A., Wang, X., Chiba, Y., Jigami, Y., Margolis, R.U., and Endo, T. (2004). Demonstration of mammalian protein O-mannosyltransferase activity: coexpression of POMT1 and POMT2 required for enzymatic activity. Proc. Natl. Acad. Sci. U. S. A. 101, 500-505.

Manya, H., and Endo, T. (2017). Glycosylation with ribitol-phosphate in mammals: New insights into the O-mannosyl glycan. Biochimica et Biophysica Acta 1861, 24622472. 
Mato, S., Del Olmo, E., and Pazos, A. (2003). Ontogenetic development of cannabinoid receptor expression and signal transduction functionality in the human brain: Ontogeny of CB1receptors in human brain. Eur. J. Neurosci. 17, 1747-1754.

Michele, D.E., Barresi, R., Kanagawa, M., Saito, F., Cohn, R.D., Satz, J.S., Dollar, J., Nishino, I., Kelley, R.I., Somer, H., et al. (2002). Post-translational disruption of dystroglycan-ligand interactions in congenital muscular dystrophies. Nature 418, 417-422.

Miller, D.S., and Wright, K.M. (2021). Neuronal Dystroglycan regulates postnatal development of CCK/cannabinoid receptor-1 interneurons. Neural Dev. 16, 4.

Moizard, M.P., Toutain, A., Fournier, D., Berret, F., Raynaud, M., Billard, C., Andres, C., and Moraine, C. (2000). Severe cognitive impairment in DMD: obvious clinical indication for Dp71 isoform point mutation screening. Eur. J. Hum. Genet. 8, $552-556$.

Monory, K., Polack, M., Remus, A., Lutz, B., and Korte, M. (2015). Cannabinoid CB1 receptor calibrates excitatory synaptic balance in the mouse hippocampus. J. Neurosci. 35, 3842-3850.

Moore, C.J., and Winder, S.J. (2010). Dystroglycan versatility in cell adhesion: a tale of multiple motifs. Cell Commun. Signal. 8, 3.

Morozov, Y.M., and Freund, T.F. (2003a). Postnatal development and migration of cholecystokinin-immunoreactive interneurons in rat hippocampus. Neuroscience $120,923-939$.

Morozov, Y.M., and Freund, T.F. (2003b). Post-natal development of type 1 cannabinoid receptor immunoreactivity in the rat hippocampus. Eur J Neurosci $18,1213-1222$.

Morozov, Y.M., Torii, M., and Rakic, P. (2009). Origin, early commitment, migratory routes, and destination of cannabinoid type 1 receptor-containing interneurons. Cereb Cortex 19 Suppl 1, i78-89.

Mulder, J., Aguado, T., Keimpema, E., Barabás, K., Ballester Rosado, C. J., Nguyen, L., Monory, K., Marsicano, G., Di Marzo, V., Hurd, Y. L., Guillemot, F., Mackie, K., Lutz, B., Guzmán, M., Lu, H. C., Galve-Roperh, I., \& Harkany, T. (2008).

Endocannabinoid signaling controls pyramidal cell specification and long-range axon patterning. Proc Natl Acad Sci U S A 105(25), 8760-8765.

Muntoni, F., Brockington, M., Godfrey, C., Ackroyd, M., Robb, S., Manzur, A., Kinali, M., Mercuri, E., Kaluarachchi, M., Feng, L., et al. (2007). Muscular dystrophies due to defective glycosylation of dystroglycan. Acta Myol. 26, 129-135. 
Muntoni, F., Torelli, S., Wells, D.J., and Brown, S.C. (2011). Muscular dystrophies due to glycosylation defects: diagnosis and therapeutic strategies. Curr. Opin. Neurol. 24, 437-442.

Myshrall, T.D., Moore, S.A., Ostendorf, A.P., Satz, J.S., Kowalczyk, T., Nguyen, H., Daza, R.A., Lau, C., Campbell, K.P., and Hevner, R.F. (2012). Dystroglycan on radial glia end feet is required for pial basement membrane integrity and columnar organization of the developing cerebral cortex. Journal of Neuropathology and Experimental Neurology 71, 1047-1063.

Naidoo, M., and Anthony, K. (2020). Dystrophin Dp71 and the neuropathophysiology of Duchenne muscular dystrophy. Mol. Neurobiol. 57, 1748-1767.

Nguyen, H., Ostendorf, A.P., Satz, J.S., Westra, S., Ross-Barta, S.E., Campbell, K.P., and Moore, S.A. (2013). Glial scaffold required for cerebellar granule cell migration is dependent on Dystroglycan function as a receptor for basement membrane proteins. Acta Neuropathol. Commun. 1, 58.

Nguyen, R., Venkatesan, S., Binko, M., Bang, J. Y., Cajanding, J. D., Briggs, C., Sargin, D., Imayoshi, I., Lambe, E. K., \& Kim, J. C. (2020). Cholecystokinin-Expressing Interneurons of the Medial Prefrontal Cortex Mediate Working Memory Retrieval. J Neurosci 40(11), 2314-2331.

Nickolls, A.R., and Bonnemann, C.G. (2018). The roles of Dystroglycan in the nervous system: insights from animal models of muscular dystrophy. Dis Model Mech 11.

Omori, Y., Araki, F., Chaya, T., Kajimura, N., Irie, S., Terada, K., Muranishi, Y., Tsujii, T., Ueno, S., Koyasu, T., et al. (2012). Presynaptic Dystroglycan-pikachurin complex regulates the proper synaptic connection between retinal photoreceptor and bipolar cells. J. Neurosci. 32, 6126-6137.

Orlandi, C., Omori, Y., Wang, Y., Cao, Y., Ueno, A., Roux, M.J., Condomitti, G., de Wit, J., Kanagawa, M., Furukawa, T., et al. (2018). Transsynaptic binding of orphan receptor GPR179 to Dystroglycan-Pikachurin complex is essential for the synaptic organization of photoreceptors. Cell Rep. 25, 130-145.e5.

Patrizi, A., Scelfo, B., Viltono, L., Briatore, F., Fukaya, M., Watanabe, M., Strata, P., Varoqueaux, F., Brose, N., Fritschy, J.-M., et al. (2008). Synapse formation and clustering of neuroligin-2 in the absence of GABAA receptors. Proc. Natl. Acad. Sci. U. S. A. 105, 13151-13156.

Peng, H.B., Ali, A.A., Daggett, D.F., Rauvala, H., Hassell, J.R., and Smalheiser, N.R. (1998). The relationship between perlecan and dystroglycan and its implication in the formation of the neuromuscular junction. Cell Adhesion and Communication $5,475-489$. 
Peron, S.P., Freeman, J., Iyer, V., Guo, C., and Svoboda, K. (2015). A Cellular Resolution Map of Barrel Cortex Activity during Tactile Behavior. Neuron 86, 783799.

Pettem, K.L., Yokomaku, D., Luo, L., Linhoff, M.W., Prasad, T., Connor, S.A., Siddiqui, T.J., Kawabe, H., Chen, F., Zhang, L., et al. (2013). The specific a-neurexin interactor calsyntenin-3 promotes excitatory and inhibitory synapse development. Neuron 80, 113-128.

Praissman, J.L., Live, D.H., Wang, S., Ramiah, A., Chinoy, Z.S., Boons, G.-J., Moremen, K.W., and Wells, L. (2014). B4GAT1 is the priming enzyme for the LARGE-dependent functional glycosylation of $\alpha$-Dystroglycan. Elife 3

Praissman, J.L., Willer, T., Sheikh, M.O., Toi, A., Chitayat, D., Lin, Y.-Y., Lee, H., Stalnaker, S.H., Wang, S., Prabhakar, P.K., et al. (2016). The functional Omannose glycan on $\alpha$-dystroglycan contains a phospho-ribitol primed for matriglycan addition. Elife 5.

Qiao, C., Wang, C.-H., Zhao, C., Lu, P., Awano, H., Xiao, B., Li, J., Yuan, Z., Dai, Y., Martin, C.B., et al. (2014). Muscle and heart function restoration in a limb girdle muscular dystrophy 2I (LGMD2I) mouse model by systemic FKRP gene delivery. Mol. Ther. 22, 1890-1899.

Reissner, C., Stahn, J., Breuer, D., Klose, M., Pohlentz, G., Mormann, M., and Missler, M. (2014). Dystroglycan binding to alpha-neurexin competes with neurexophilin-1 and neuroligin in the brain. J Biol Chem 289, 27585-27603.

Roscioli, T., Kamsteeg, E.-J., Buysse, K., Maystadt, I., van Reeuwijk, J., van den Elzen, C., van Beusekom, E., Riemersma, M., Pfundt, R., Vissers, L.E.L.M., et al. (2012). Mutations in ISPD cause Walker-Warburg syndrome and defective glycosylation of a-Dystroglycan. Nat. Genet. 44, 581-585.

Rovira-Esteban, L., Gunduz-Cinar, O., Bukalo, O., Limoges, A., Brockway, E., Muller, K., Fenno, L., Kim, Y.S., Ramakrishnan, C., Andrasi, T., et al. (2019). Excitation of Diverse Classes of Cholecystokinin Interneurons in the Basal Amygdala Facilitates Fear Extinction. eNeuro 6.

Sato, S., Omori, Y., Katoh, K., Kondo, M., Kanagawa, M., Miyata, K., Funabiki, K., Koyasu, T., Kajimura, N., Miyoshi, T., et al. (2008). Pikachurin, a dystroglycan ligand, is essential for photoreceptor ribbon synapse formation. Nature Neuroscience 11, 923-931.

Satz, J.S., Barresi, R., Durbeej, M., Willer, T., Turner, A., Moore, S.A., and Campbell, K.P. (2008). Brain and eye malformations resembling Walker-Warburg syndrome are recapitulated in mice by dystroglycan deletion in the epiblast. J. Neurosci. 28, 10567-10575. 
Satz, J.S., Philp, A.R., Nguyen, H., Kusano, H., Lee, J., Turk, R., Riker, M.J., Hernández, J., Weiss, R.M., Anderson, M.G., et al. (2009). Visual impairment in the absence of dystroglycan. J. Neurosci. 29, 13136-13146.

Satz, J.S., Ostendorf, A.P., Hou, S., Turner, A., Kusano, H., Lee, J.C., Turk, R., Nguyen, H., Ross-Barta, S.E., Westra, S., et al. (2010). Distinct functions of glial and neuronal dystroglycan in the developing and adult mouse brain. The Journal of Neuroscience 30, 14560-14572.

Schindelin, J., Arganda-Carreras, I., Frise, E., Kaynig, V., Longair, M., Pietzsch, T., Preibisch, S., Rueden, C., Saalfeld, S., Schmid, B., et al. (2012). Fiji: an opensource platform for biological-image analysis. Nat Methods 9, 676-682.

Sudhof, T.C. (2018). Towards an Understanding of Synapse Formation. Neuron 100, 276-293.

Sugita, S., Saito, F., Tang, J., Satz, J., Campbell, K., and Sudhof, T.C. (2001). A stoichiometric complex of neurexins and dystroglycan in brain. The Journal of Cell Biology 154, 435-445.

Sugiyama, J., Bowen, D.C., and Hall, Z.W. (1994). Dystroglycan binds nerve and muscle agrin. Neuron 13, 103-115.

Sultan, K.T., Brown, K.N., and Shi, S.-H. (2013). Production and organization of neocortical interneurons. Front. Cell. Neurosci. 7, 221.

Tai, Y., Gallo, N.B., Wang, M., Yu, J.R., and Van Aelst, L. (2019). Axo-axonic Innervation of Neocortical Pyramidal Neurons by GABAergic Chandelier Cells Requires AnkyrinG-Associated L1CAM. Neuron 102, 358-372 e359.

Takahashi, H., Katayama, K.-I., Sohya, K., Miyamoto, H., Prasad, T., Matsumoto, Y., Ota, M., Yasuda, H., Tsumoto, T., Aruga, J., et al. (2012). Selective control of inhibitory synapse development by Slitrk3-PTPס trans-synaptic interaction. Nat. Neurosci. 15, 389-398, S1-2.

Taniguchi-Ikeda, M., Morioka, I., Iijima, K., and Toda, T. (2016). Mechanistic aspects of the formation of alpha-dystroglycan and therapeutic research for the treatment of alpha-dystroglycanopathy: A review. Molecular Aspects of Medicine 51, 115-124.

Tian, M., Jacobson, C., Gee, S.H., Campbell, K.P., Carbonetto, S., and Jucker, M. (1996). Dystroglycan in the cerebellum is a laminin alpha 2-chain binding protein at the glial-vascular interface and is expressed in Purkinje cells. Eur. J. Neurosci. 8, 2739-2747. 
Tronche, F., Kellendonk, C., Kretz, O., Gass, P., Anlag, K., Orban, P.C., Bock, R., Klein, R., and Schütz, G. (1999). Disruption of the glucocorticoid receptor gene in the nervous system results in reduced anxiety. Nat. Genet. 23, 99-103.

Ullrich, B., Ushkaryov, Y.A., and Südhof, T.C. (1995). Cartography of neurexins: more than 1000 isoforms generated by alternative splicing and expressed in distinct subsets of neurons. Neuron 14, 497-507.

van Reeuwijk, J., Janssen, M., van den Elzen, C., Beltran-Valero de Bernabé, D., Sabatelli, P., Merlini, L., Boon, M., Scheffer, H., Brockington, M., Muntoni, F., et al. (2005). POMT2 mutations cause alpha-Dystroglycan hypoglycosylation and Walker-Warburg syndrome. J. Med. Genet. 42, 907-912.

Veres, J.M., Nagy, G.A., and Hájos, N. (2017). Perisomatic GABAergic synapses of basket cells effectively control principal neuron activity in amygdala networks. Elife 6.

Vitalis, T., Lainé, J., Simon, A., Roland, A., Leterrier, C., \& Lenkei, Z. (2008). The type 1 cannabinoid receptor is highly expressed in embryonic cortical projection neurons and negatively regulates neurite growth in vitro. The European journal of neuroscience, 28(9), 1705-1718.

Wang, X., Dow-Edwards, D., Keller, E., and Hurd, Y.L. (2003). Preferential limbic expression of the cannabinoid receptor mRNA in the human fetal brain. Neuroscience 118, 681-694.

Whissell, P.D., Bang, J.Y., Khan, I., Xie, Y.F., Parfitt, G.M., Grenon, M., Plummer, N.W., Jensen, P., Bonin, R.P., and Kim, J.C. (2019). Selective Activation of Cholecystokinin-Expressing GABA (CCK-GABA) Neurons Enhances Memory and Cognition. eNeuro 6.

Willer, T., Lee, H., Lommel, M., Yoshida-Moriguchi, T., de Bernabe, D.B.V., Venzke, D., Cirak, S., Schachter, H., Vajsar, J., Voit, T., et al. (2012). ISPD loss-of-function mutations disrupt Dystroglycan O-mannosylation and cause Walker-Warburg syndrome. Nat. Genet. 44, 575-580.

Willer, T., Inamori, K.-I., Venzke, D., Harvey, C., Morgensen, G., Hara, Y., Beltrán Valero de Bernabé, D., Yu, L., Wright, K.M., and Campbell, K.P. (2014). The glucuronyltransferase B4GAT1 is required for initiation of LARGE-mediated $\alpha$ Dystroglycan functional glycosylation. Elife 3.

Williamson, R.A., Henry, M.D., Daniels, K.J., Hrstka, R.F., Lee, J.C., Sunada, Y., Ibraghimov-Beskrovnaya, O., and Campbell, K.P. (1997). Dystroglycan is essential for early embryonic development: disruption of Reichert's membrane in Dag1-null mice. Hum Mol Genet 6, 831-841. 
Wright, K.M., Lyon, K.A., Leung, H., Leahy, D.J., Ma, L., and Ginty, D.D. (2012). Dystroglycan organizes axon guidance cue localization and axonal pathfinding. Neuron 76, 931-944.

Zaccaria, M.L., Di Tommaso, F., Brancaccio, A., Paggi, P., and Petrucci, T.C. (2001). Dystroglycan distribution in adult mouse brain: a light and electron microscopy study. Neuroscience 104, 311-324. 